
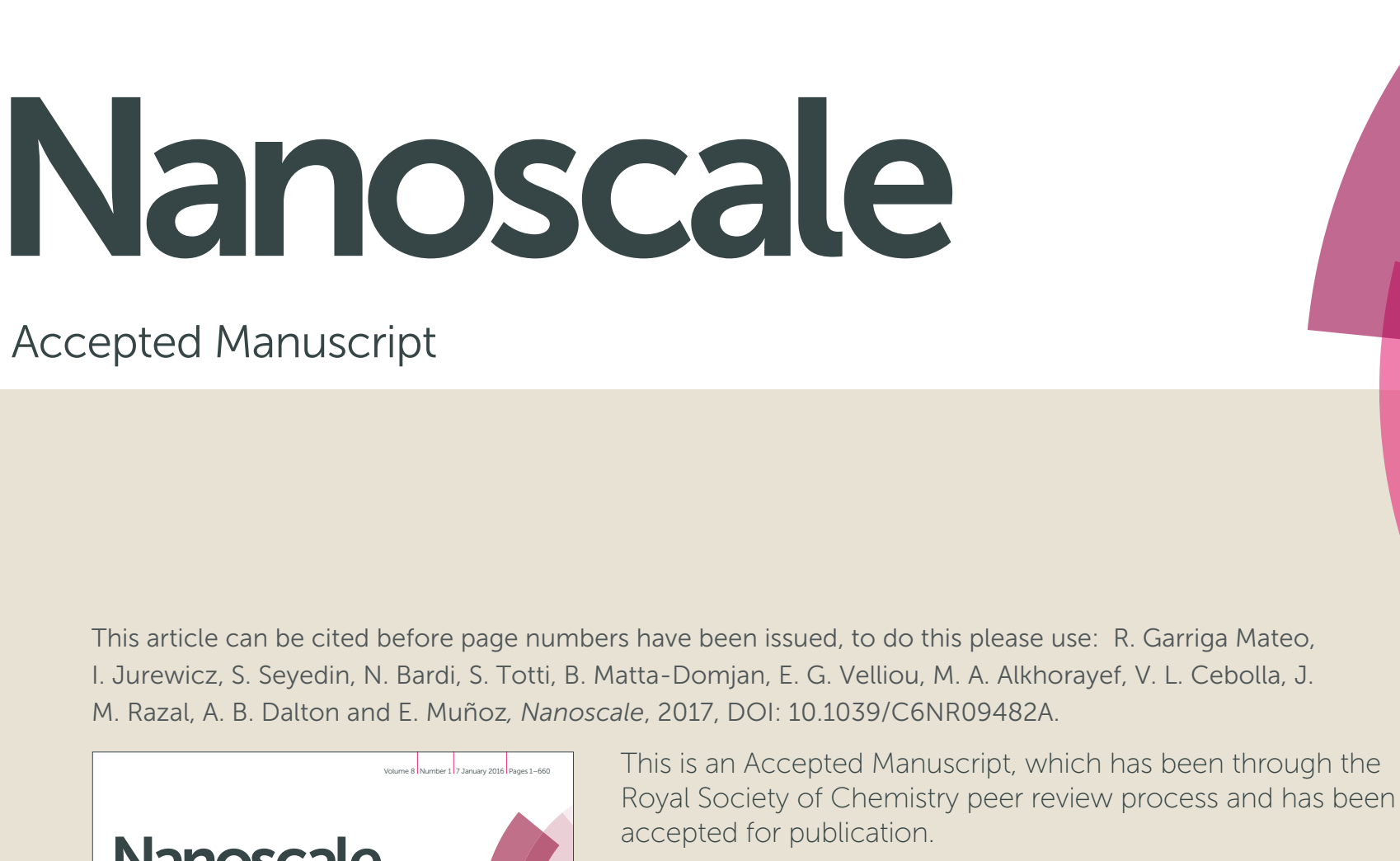

This article can be cited before page numbers have been issued, to do this please use: R. Garriga Mateo, I. Jurewicz, S. Seyedin, N. Bardi, S. Totti, B. Matta-Domjan, E. G. Velliou, M. A. Alkhorayef, V. L. Cebolla, J. M. Razal, A. B. Dalton and E. Muñoz, Nanoscale, 2017, DOI: 10.1039/C6NR09482A.

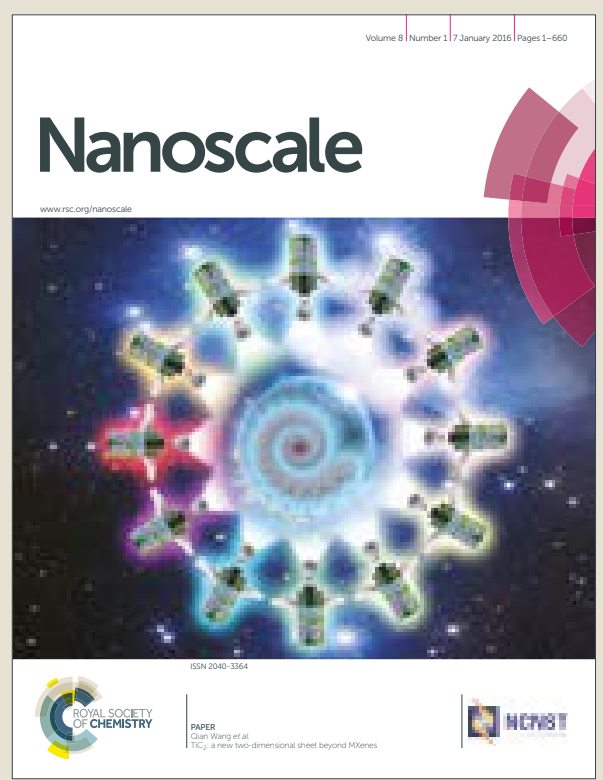

This is an Accepted Manuscript, which has been through the Royal Society of Chemistry peer review process and has been accepted for publication.

Accepted Manuscripts are published online shortly after acceptance, before technical editing, formatting and proof reading. Using this free service, authors can make their results available to the community, in citable form, before we publish the edited article. We will replace this Accepted Manuscript with the edited and formatted Advance Article as soon as it is available.

You can find more information about Accepted Manuscripts in the author guidelines.

Please note that technical editing may introduce minor changes to the text and/or graphics, which may alter content. The journal's standard Terms \& Conditions and the ethical guidelines, outlined in our author and reviewer resource centre, still apply. In no event shall the Royal Society of Chemistry be held responsible for any errors or omissions in this Accepted Manuscript or any consequences arising from the use of any information it contains. 
Received 00th January 20xx, Accepted 00th January 20xx

DOI: $10.1039 / \times 0 \times x 00000 x$

www.rsc.org/

\title{
Multifunctional, Biocompatible and pH-Responsive Carbon Nanotube- and Graphene Oxide/Tectomer Hybrid Composites and Coatings
}

\author{
Rosa Garriga, ${ }^{\text {a }}$ Izabela Jurewicz, ${ }^{\text {b }}$ Shayan Seyedin, ${ }^{\mathrm{c}}$ Niki Bardi, ${ }^{\mathrm{b}}$ Stella Totti, ${ }^{\mathrm{d}}$ Brigitta Matta- \\ Domjan, ${ }^{d}$ Eirini G. Velliou, ${ }^{d}$ Mohammed A. Alkhorayef, ${ }^{e}$ Vicente L. Cebolla, ${ }^{f}$ Joselito M. Razal, ${ }^{c}$ Alan \\ B. Daltong and Edgar Muñoz ${ }^{* f}$
}

\begin{abstract}
Here we present a route for non-covalent functionalization of carboxylated multi-wall carbon nanotubes and graphene oxide with novel two-dimensional peptide assemblies. We show that self-assembled amino-terminated biantennary and tetraantennary oligoglycine peptides (referred to as tectomers) effectively coat carboxylated multi-walled carbon nanotubes and also strongly interact with graphene oxide due to electrostatic interactions and hydrogen bonding as the driving force, respectively. The resulting hybrids can be made into free-standing conducting composites or applied in the form of thin, $\mathrm{pH}$-switchable bioadhesive coatings onto graphene oxide fibers. Monitoring of cell viability of pancreatic cell lines, seeded on those CNT hybrids, show that they can be used as two- and three-dimensional scaffolds to tissue engineer tumour models for studying ex vivo the tumour development and response to treatment. This highly versatile method in producing $\mathrm{pH}$-responsive hybrids and coatings offers an attractive platform for a variety of biomedical applications and for the development of functional materials such as smart textiles, sensors and bioelectronic devices.
\end{abstract}

\section{Introduction}

The versatile chemistry of biomolecules provides an intriguing and sophisticated means to incorporate nano-building blocks into biological environments as well as into supramolecular structures by self-assembly. ${ }^{1-7}$ Such processes can be suitably controlled by tuning the experimental conditions such as $\mathrm{pH}$, solvent, temperature and composition, offering new opportunities for designing smart, functional materials and odevices for a range of biomedical and technological applications. ${ }^{8-10} \quad$ Peptides, lipids, polynucleotides, polysaccharides, as well as polymers, gelators, and surfactants use these biomimetics to bind to and efficiently disperse carbon nanomaterials such as carbon nanotubes (CNTs) and

a. Departamento de Química Física, Universidad de Zaragoza, 50009 Zaragoza, Spain

b. Department of Physics, Faculty of Engineering \& Physical Sciences, University of Surrey, Guildford GU2 7XH, United Kingdom

E-mail: izabela.jurewicz@surrey.ac.uk

Deakin University, Institute for Frontier Materials, Geelong 3220 Victoria, Australia

d. Bioprocess and Biochemical Engineering group (BioProChem), Department of Chemical and Process Engineering, Faculty of Engineering \& Physical Sciences, University of Surrey, Guildford, GU2 7XH, United Kingdom

e. Department of Radiological Sciences, College of Applied Medical Sciences, King Saud University, Riyadh 11433, Saudi Arabia

f. Instituto de Carboquímica ICB-CSIC, Miguel Luesma Castán 4, 50018 Zaragoza, Spain.E-mail:edgar@icb.csic.es

g. Department of Physics, University of Sussex, Brighton, BN1 9RH, United Kingdom + Electronic Supplementary Information (ESI) available: Contact angle measurements; additional microscopy and XPS studies; UV-vis studies and movie showing tectomer-assisted GO flocculation; See DOI: 10.1039/x0xx00000x graphene oxide (GO) in aqueous and biological media. Such dispersing approaches facilitate the bottom-up formation of highly ordered structures resulting in fascinating synergies, affording additional functions useful for a large number of applications ranging from sensing, catalysis, drug delivery and to tissue engineering. ${ }^{11-30}$

In this regard, the use of de novo peptides, whose sequence, length, structure and assembly can be conveniently tailored, is an efficient and elegant route for the preparation of stable CNT dispersions, ${ }^{31-36}$ as well as for the directed incorporation of CNT building blocks into hierarchical structures $^{31,37-40}$ and functional devices. ${ }^{41-43}$ In particular, peptide-functionalized nanomaterials are increasingly playing an important role in tissue and biomedical engineering for the development of novel synthetic scaffolds for cell culture in vitro that closely resemble in vivo conditions and show improved biomimetic properties. ${ }^{44-47}$

Oligoglycines are examples of synthetic peptides with exceptional self-assembly capabilities. Amino-terminated bi-, tri-, and tetraantennary oligoglycines non-covalently assemble, through cooperative hydrogen bonding formation, into biocompatible rigid, two-dimensional (2D) structures called tectomers, either in solution or in surface-promoted processes. ${ }^{48,49}$

The unique self-assembly features of amino-terminated oligoglycine have been successfully exploited to coat negatively-charged surfaces, such as mica ${ }^{48,50}$ and bacteria membranes, ${ }^{51}$ viruses through oligoglycine glycosylation, ${ }^{50,52,53}$ and polymer fibers by covalent functionalization. ${ }^{54}$ 
Furthermore, we have recently demonstrated the capabilities of tectomers as efficient $\mathrm{pH}$-sensitive nanocarriers, making them extremely attractive for biosensing and therapeutic applications. ${ }^{55}$ To the contrary, although from the same family, oligoglycine-based bolaamphiphiles that possess carboxylic (instead of amino) head groups do not assemble as tectomers but as vesicles and microtubes, because of the electrostatic repulsion between ionized carboxylic groups. ${ }^{56,57}$

Tectomers have the ability to form extensive, surface adaptive, ultrathin coatings and, on top of that, are biocompatible and may act as biointerfaces. This, together with the atomically smooth rigid 2D structure (which is very unique to this system), $\mathrm{pH}$-responsive nature and chemical reactivity of their terminal amino groups are attributes that make tectomers very appealing as platforms for engineering novel functional layered biomaterials. Hybrid materials that efficiently utilize these tectomer features, as well as the outstanding physicochemical properties of CNTs and GO, may be of interest in biomedicine and for a variety of other technological applications.

Here we report, for the first time, on the formation of oligoglycine tectomer hybrids with CNTs and GO. We provide evidence that the different structural features of CNTs and GO significantly affect their interaction with amino-terminated biantennary and tetraantennary oligoglycine peptides (hereafter designated as $2 \mathrm{~T}$ and $4 \mathrm{~T}$ tectomers). The molecular structures together with the schemas of their 2D tectomer assemblies are shown in Fig. 1. Our results show that tectomers provide adhesive properties and enhanced stability to the tested coatings and assemblies. Their strong interfacial interaction with both CNTs and GO in these hybrids can be efficiently controlled by adjusting the $\mathrm{pH}$. In addition, we show that such CNT/tectomer hybrids can form efficient coatings on GO fibers and consequently can be used as $2 \mathrm{D}$ and ultimately 3D scaffolds for culture of cells, therefore, providing interesting in vitro human cell culture models.

\section{Materials and Methods}

\subsection{Materials}

Amino-terminated biantennary (2T) and tetraantennary (4T) oligoglycine peptides, $\mathrm{C}_{8} \mathrm{H}_{16}\left(-\mathrm{CH}_{2}-\mathrm{NH}-\mathrm{Gly}_{5}\right)_{2} \cdot 2 \mathrm{HCl}$ and $\mathrm{C}\left(-\mathrm{CH}_{2}-\mathrm{NH}-\right.$ $\left.\mathrm{Gly}_{7}\right)_{4} \cdot 4 \mathrm{HCl}$, respectively, purity > $95 \%$, were supplied by PlasmaChem $\mathrm{GmbH}$ and used as received. Oligoglycine solutions in ultrapure water (Siemens LaboStar DI/UV 2 system, resistivity: 18.2 $\mathrm{M} \Omega \mathrm{cm}$ at $25 \mathrm{\circ} C$ ) were prepared by bath sonication (100 W Branson 2510 bath sonicator) for $2 \mathrm{~min}$ and then probe sonicated (500 W Cole Parmer Ultrasonic Processor) in pulsed mode (1 s on, $3 \mathrm{~s}$ off, amplitude: $21 \%$ ) for $16 \mathrm{~min}$ (4 min of effective "on" sonication, transferred energy: $\sim 1,000 \mathrm{~J})$. Single-walled carbon nanotubes (SWCNTs) produced by the HiPco process (average diameter of $\sim 1$ $\mathrm{nm}$, and $\sim 1$ micrometer long, batch \# RO501) were purchased from Carbon Nanotechnologies, Inc. Multi-walled carbon nanotubes (MWCNTs), 20 to $40 \mathrm{~nm}$ in diameter, and carboxylated MWCNTs (MWCNT-COOH), 18.0 wt.\% oxygen, 70.5 wt.\% carbon, were purchased from PlasmaChem $\mathrm{GmbH}$. GO (44.9 wt.\% oxygen, 44.6 wt.\% carbon) was supplied by CheapTubes Inc. MWCNT-CQQH

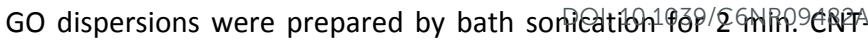
and $\mathrm{GO} /$ oligoglycine peptide dispersions were prepared by mixing oligoglycine peptide solutions with CNT or GO solutions with a volume ratio $1: 1$, followed by the probe sonication procedure described above in the case of CNTs. Except otherwise stated, final concentration of all species was $1 \mathrm{mg} \mathrm{mL}^{-1}$. Typical volumes of the prepared hybrid dispersions were in the 4 to $8 \mathrm{~mL}$ range.

$\mathrm{pH}$ values of solutions were measured using a Crison Basic 20 $\mathrm{pH}$ meter. Due to its low electrical conductivity, reliable $\mathrm{pH}$ measurements of ultrapure water were achieved by adding $\mathrm{KCl}$, and the $\mathrm{pH}$ value of 6.5 was obtained. In the case of oligoglycine solutions, $\mathrm{pH}$ values depend on concentration, due to $\mathrm{HCl}$ coming from oligoglycine synthesis. ${ }^{49,55}$ Thus, for $2 \mathrm{mg} \mathrm{mL}^{-1}, 1 \mathrm{mg} \mathrm{mL}^{-1}$ and $0.5 \mathrm{mg} \mathrm{mL}^{-1} 2 \mathrm{~T}$ solutions in water, $\mathrm{pH}$ was $5.2,5.6$, and 5.8 , respectively, while in the case of $4 \mathrm{~T}, \mathrm{pH}$ was $5.7,6.0$, and 6.1. Buffer $\mathrm{pH} 12.0$ was purchased from Aldrich, while buffer $\mathrm{pH} 7.4$ and buffer $\mathrm{pH} 2.2$ were prepared from $\mathrm{Na}_{2} \mathrm{HPO}_{4}$ and $\mathrm{NaH}_{2} \mathrm{PO}_{4}$ solutions, and from citric acid and $\mathrm{Na}_{2} \mathrm{HPO}_{4}$ solutions, respectively.

\subsection{GO fiber spinning and coatings}

GO fibers, $\sim 60$ micrometers in diameter, were wet-spun as reported elsewhere. ${ }^{58} \mathrm{In}$ brief, $5 \mathrm{mg} \mathrm{mL}^{-1}$ liquid crystalline $\mathrm{GO}$ dispersions were coagulated in calcium chloride bath, rinsed with ethanol, and then dried in air under tension. According to X-ray photoelectron spectroscopy analysis, the $\mathrm{C}: \mathrm{O}$ atomic ratio for the $\mathrm{GO}$ material used was 2.01. GO fibers were coated with tectomers by impregnation in oligoglycine solutions carried out for $18 \mathrm{~h}$. The resulting $\mathrm{GO} /$ tectomer fibers were coated in a second step with MWCNT-COOH by impregnation in MWCNT-COOH dispersions for 18 h. Alternatively, GO fibers were coated with MWCNT$\mathrm{COOH} /$ tectomer hybrids directly by impregnation in MWCNT$\mathrm{COOH} /$ oligoglycine solutions for $18 \mathrm{~h}$. Each coating step was followed by a $3 \mathrm{~h}$ immersion in water to remove non-specifically bound materials and to assess the stability of the coatings.

\subsection{MWCNT/tectomer free-standing films}

MWCNT- $\mathrm{COOH} /$ tectomer free-standing films were prepared by drop casting $0.7 \mathrm{~mL}$ of MWCNT-COOH/oligoglycine solutions on Millipore Mitex ${ }^{\mathrm{TM}}$ PTFE filter membranes (pore size $10 \mu \mathrm{m}$ ). Fourprobe electrical conductivities of strips of these films were calculated from resistance values measured using a Keithley 2000 Multimeter.

\subsection{Electron microscopy characterization}

Transmission electron microscopy (TEM) characterization was conducted using a TECNAI T20 microscope. Samples for TEM imaging were prepared by depositing a droplet of the solutions onto carbon-coated copper grids that are then allowed to dry under ambient conditions after wicking away most of the solution. For buffer $\mathrm{pH} 2.2$ samples, phosphotungstic acid were used as staining agent to distinguish vesicular structures. Scanning electron microscopy (SEM) characterization of tectomers/GO hybrids dried on Al foil and of coated GO fibers was performed with an Inspect F50 field emission SEM microscope. In order to image the structural features of the peptide assemblies in solution, brightfield images 
were obtained using a Leica SP5 laser scanning confocal microscope (LSCM) equipped with a $63 \times 1.4$ NA HCX PL APO oil immersion objective. Also the prepared dispersions were characterized by environmental scanning electronic microscopy (ESEM, Quanta FEG 250 ESEM microscope, FEI Company). The ESEM microscope chamber pressure and sample temperature were set at $650 \mathrm{~Pa}$ and $1 \stackrel{\circ}{ } \mathrm{C}$, respectively, which leads to a $100 \%$ relative humidity.

\subsection{Atomic force microscopy characterization}

Atomic force microscopy (AFM) studies were performed using a NTEGRA AFM microscope (NT-MDT) operating in semicontact mode. AFM probes (Nanosensors ${ }^{\mathrm{TM}}$ ) with a force constant ranging from 10 to $130 \mathrm{~N} \mathrm{~m}^{-1}$ were used. All images were corrected for the tilt of the sample and background subtraction was employed. One drop of the prepared oligoglycine peptide solutions were spincoated onto a freshly cleaved mica substrate (at $3000 \mathrm{rpm}$ for $7 \mathrm{~s}$ ). The substrate was spun again twice at the same speed and time, to remove excess of non-specifically adsorbed material.

\subsection{X-Ray photoelectron spectroscopy}

X-ray photoelectron spectroscopy (XPS) was performed on aqueous solutions dried on Al foil using an ESCA Plus Omicron spectrometer provided with a Mg anode (1253.6 eV) working at $225 \mathrm{~W}$ (15 mA, 15 $k \mathrm{~V})$. When required, binding energy (BE) positions were corrected by setting the aromatic C1s component at a BE of $284.5 \mathrm{eV}$. CASA software was used for the peak deconvolution and Shirley type baseline correction was applied.

\subsection{Absorption spectroscopy}

Absorption UV-vis spectra were recorded on a Shimadzu UV-1800 spectrophotometer and was used to monitor the removal of tectomers from solution upon precipitation in experiments with GO.

\subsection{Contact angle measurements}

Contact angle measurements were performed using a KRÜSS Drop Shape Analyzer DSA 100 system. $200 \mu \mathrm{L}$ of the tested solutions were drop-cast on glass microscope slides (Ghäasel) and left to dry overnight. $4 \mu \mathrm{L}$ ultrapure water droplets were deposited onto peptide-coated surfaces by means of an automatic dosifier at room temperature $\left(22^{\circ} \mathrm{C}\right)$. Contact angle values were calculated from high resolution optical photographs of the deposited drops using a digital image processing software. At least six measurements were performed for each sample.

\subsection{Zeta-Potential measurements}

A Malvern Zetasizer NanozS instrument, equipped with a with a 4 $\mathrm{mW} 632.8 \mathrm{~nm}$ He-Ne laser, has been used to measure the

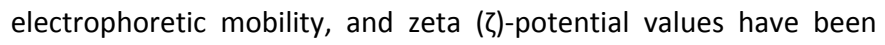
calculated from the Henry equation, using the Smoluchowski model. $2 \mathrm{~T}$, MWCNT-COOH and MWCNT- $\mathrm{COOH} / 2 \mathrm{~T}$ dispersions were prepared in water, at room temperature $25 \circ \mathrm{C}$. In these samples, $2 \mathrm{~T}$ concentration was $0.5 \mathrm{mg} \cdot \mathrm{mL}^{-1}$, whereas that of MWCNT-COOH was as low as $0.0025 \mathrm{mg} \cdot \mathrm{mL}^{-1}$ to obtain optically clear samples.

\subsection{Cell viability studies}

View Article Online DOI: 10.1039/C6NR09482A For cell viability studies, pristine tectomer, MWCNT-COOH, and MWCNT-COOH/tectomer hybrid samples were drop-cast in a standard polystyrene 96-well plate (Thermo Fisher Scientific), air-dried, and sterilized for 10 minutes in a UV/ozone generator (BioForce Nanosciences). Cell viability/growth on the tested samples was assessed by the MTS spectrophotometric assay (CellTiter 96 ${ }^{\circledR}$ AQueous One Solution Cell Proliferation kit; Promega Corporation) based on the metabolic activity of cells. The viability of three pancreatic adenocarcinoma cell lines, i.e., AsPC-1, PANC-1 and BxPC-3, was monitored. AsPC-1 and PANC-1 cells were cultured in DMEM growth medium with high-glucose $(4.5 \mathrm{~g} / \mathrm{L})$ (Lonza Ltd) supplemented with $2 \mathrm{mM}$ L-glutamine (Sigma-Aldrich), 10\% foetal bovine serum (Invitrogen) and $100 \mathrm{U} / \mathrm{mL}$ PenicillinStreptomycin (Invitrogen). BxPC-3 cells were cultured in RPMI1640 medium (Lonza Ltd) supplemented with glutamine and penicillin-strepromycin as described above for DMEM. The $\mathrm{pH}$ of the culture media was 7.0-7.6. The medium was replaced frequently, therefore assuring no significant $\mathrm{pH}$ drop due to cell metabolism/activity. Cells were grown at a density of $10^{4}$ cells/well in an incubator at $37 \circ \mathrm{C}$ and $5 \% \mathrm{CO}_{2}$ for up to 4 days, and cell viability measurements were carried out at three time points, i.e., one, two and four days after seeding (day 1, day 2 and day 4). Wells without pristine tectomer, MWCNT-COOH or MWCNT-COOH/tectomer were used as controls. The measured absorbance is directly proportional to the number of viable cells. Two independent experiments $(\mathrm{N}=2)$ were carried out, and two wells were tested for each time point $(n=2)$.

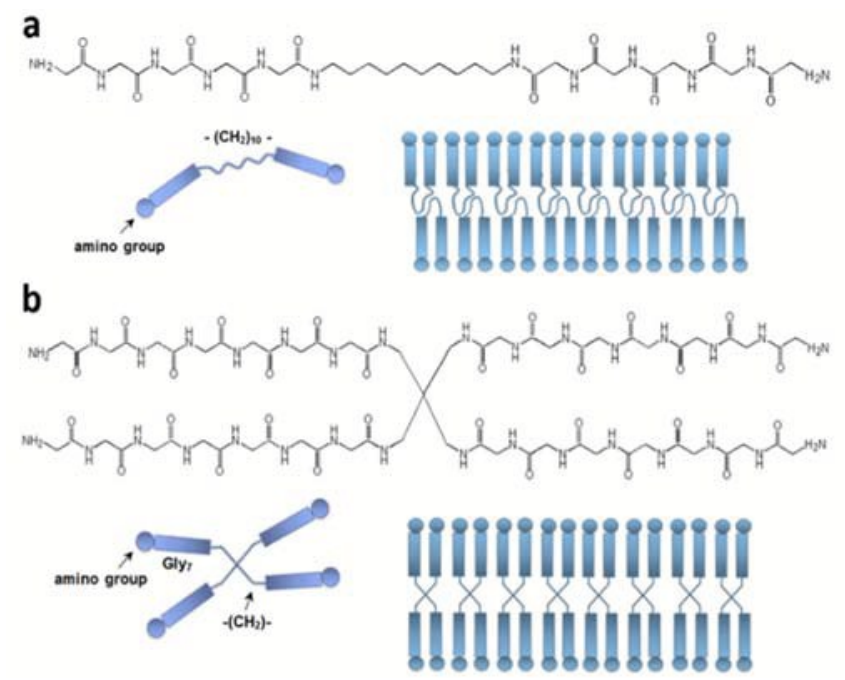

Fig. 1 Molecular structures of (a) $2 \mathrm{~T}$ and (b) $4 \mathrm{~T}$, and scheme of association in two-dimensional self-assemblies (tectomers), stabilized by extensive networks of hydrogen bonds between the antennae. 
a

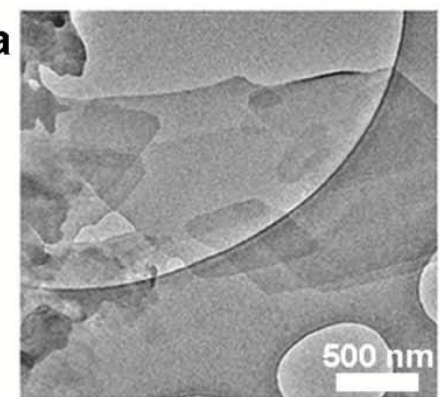

b

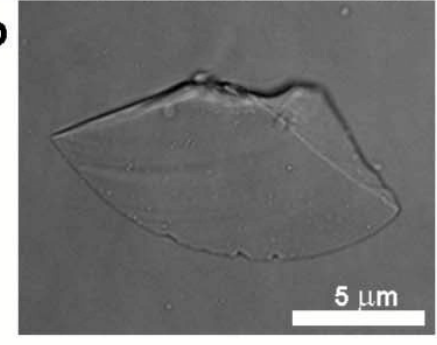

C
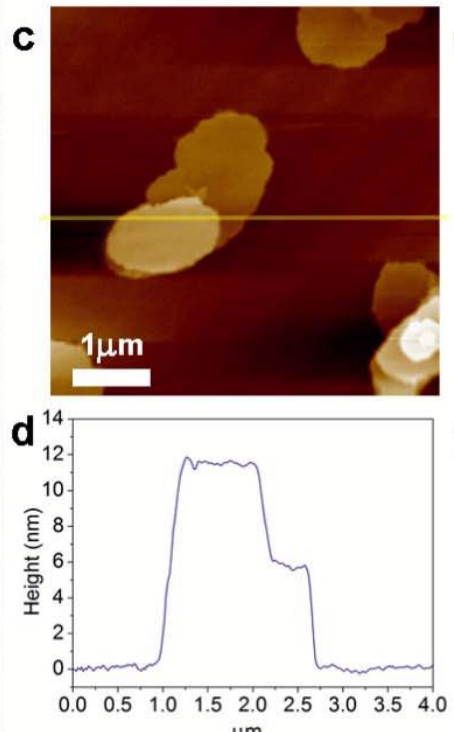

\section{e}

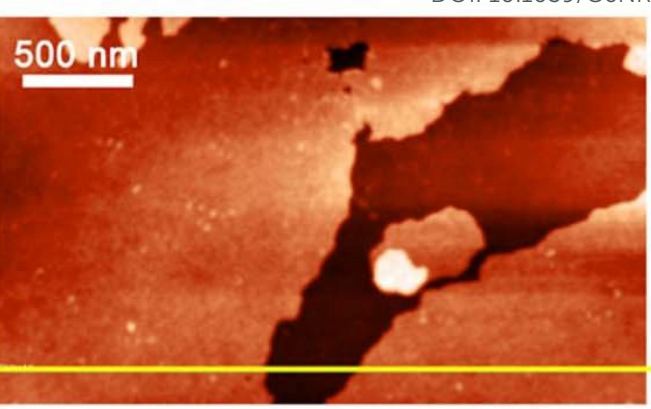

f

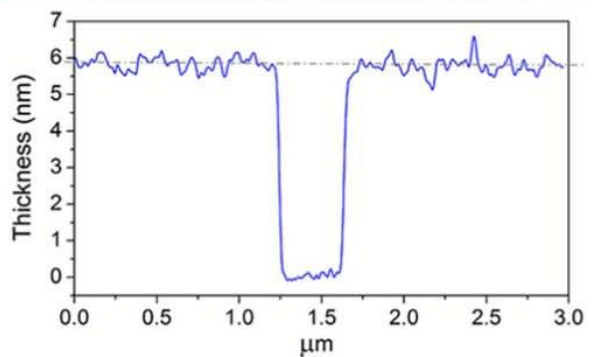

Fig. 2 (a) TEM and (b) bright field microscopy characterization of tectomers prepared from $1 \mathrm{mg} \mathrm{mL}^{-1} 2 \mathrm{~T}$ solution in water ( $\mathrm{pH} 5.6$ ). AFM characterization: (c) phase image and (d) corresponding line profile, showing $\sim 5.6 \mathrm{~nm}$ thick individual tectomer platelets deposited on mica. Height image (e) and corresponding line profile ( $f$ ) of a large, flat and smooth $2 \mathrm{~T}$ tectomer coating on glass.

To investigate the biocompatibility of the GO fiber coated with tectomers and MWCNT-COOH/tectomer hybrids, optical microscopy was used. For the sample preparation both types of GO fibers were fixed to the bottom of a 24-well plate (Thermo Fisher Scientific) using epoxy resin as a glue. Pancreatic cancer cell lines (maintained as above) were plated at a density of $10^{5}$ cells/well (duplicates were performed) and cultured for 3 days in the prepared plate. Visual observation was performed using a Zeiss Axiovert $40 \mathrm{C}$ optical microscope with a $\times 40$ objective.

\section{Results and Discussion}

\subsection{Tectomer formation and properties}

Using a combination of scanning probe and electron microscopies, we investigate the nature of the self-assembly of $2 \mathrm{~T}$ and $4 \mathrm{~T}$, respectively (Fig. 1). Microscopy characterization of tectomers that result from $1 \mathrm{mg} \mathrm{mL}^{-1}$ solutions in water is shown in Fig. 2 and Fig. S1. The 2D nature and micrometer size of the tectomer assemblies resemble the structural features of liquid phase exfoliated graphene and other inorganic layered materials. ${ }^{59,60}$ AFM studies for $2 \mathrm{~T}$ tectomers reveal that the molecules assemble into single-layered platelets with an average thickness of $5.6 \mathrm{~nm}$, which exhibit angstrom-scale root-mean-square roughness. Extensively smooth tectomer coatings can also be formed, as shown in Fig. 2e,f. AFM and theoretical studies of structural features of the assemblies formed by oligoglycines reported elsewhere, ${ }^{48,50,52}$ show a thickness value of $4.5 \mathrm{~nm}$ for $4 \mathrm{~T}$ tectomers.
Wettability studies conducted on tectomer-coated glass substrate show that the deposited tectomer films provide enhanced glass hydrophobicity upon peptide fuctionalization. Contact angle values increase from $18.6^{\circ}$ (bare substrate) to $58.5^{\circ}$ and to $88.7^{\circ}$, for $2 \mathrm{~T}$ and $4 \mathrm{~T}$ tectomer films, respectively (Fig. S2). We hypothesize that the enhanced surface hydrophobicity is due to the formation of strong electrostatic interactions between tectomers and hydrophilic surfaces, leading to the exposure of nonpolar sites on the top (Fig. S2d).

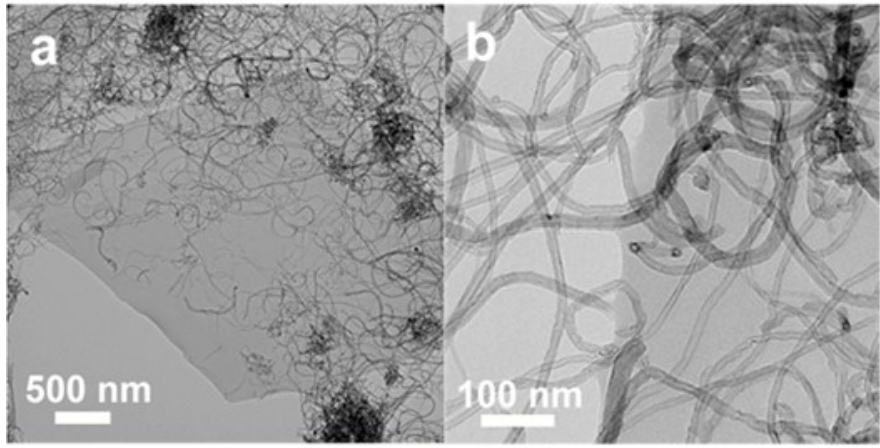

Fig. 3 (a) Low- and (b) high resolution TEM micrographs corresponding to MWCNT/2T hybrids deposited on TEM grids from water dispersions (pH 5.6), showing lack of CNT/tectomer interactions. 
The tectomers are highly $\mathrm{pH}$ sensitive, and understanding the effect of $\mathrm{pH}$ on oligoglycine assemblies is a key issue towards developing functional tectomer-based coatings. As mentioned above, oligoglycine assembly in the form of tectomers already occurs in water. $\mathrm{pH}$ shifting of the oligoglycine solutions towards alkaline condition triggers deprotonation of terminal amino groups and the loss of the associated electrostatic repulsions resulting in extended tectomer formation. Thus, $2 \mathrm{~T}$ tectomers formed at $\mathrm{pH} 7.4$ are not soluble and fall out of solution. ${ }^{55} \mathrm{pK}=9.6$ for glycine amino acid, however in tectomer assemblies the amino terminal groups are in close vicinity, and it is well-known that protonation of amino groups in polyamines electrostatically suppresses subsequent protonation processes in neighboring groups. ${ }^{61-63}$ Therefore, at $\mathrm{pH} 7.4$, a significant number of amino terminal groups in tectomer assemblies are deprotonated, which allows extended tectomer formation. On the other hand, under acidic conditions, electrostatic repulsion between neighbouring terminal amino groups, due to strong protonation, leads to tectomer disassembly, and to the formation of vesicular and tubular structures for 2T (Fig. S3a,b) and $4 \mathrm{~T}$ (Fig. S3c,d), respectively, at $\mathrm{pH}$ 2.2.

\subsection{CNT/tectomer hybrids}

Here we developed CNT/tectomer hybrids that take advantage of both the outstanding $\mathrm{pH}$-responsive 2D assembly structure/surface coating capabilities of tectomers and the unique physical properties of CNTs. ${ }^{64}$
We have shown previously, that CNTs can be successfully

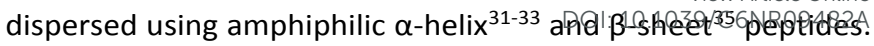
Guided by this experience, we first attempted to disperse pristine HiPco SWCNT and MWCNT in water using $2 \mathrm{~T}$ and $4 \mathrm{~T}$. However, these peptides were not successful at dispersing pristine CNTs and the resulting dispersions consisted of large aggregates. TEM characterization of these samples confirmed that there is very little interaction between tectomers and non-functionalized CNTs (Fig. 3).

In contrast, when using carboxyl surface modified multiwalled carbon nanotubes (MWCNT-COOH), uniform and stable water dispersions were obtained with both $2 \mathrm{~T}$ and $4 \mathrm{~T}$. TEM and AFM studies show extensive peptidic coating on the MWCNT-COOH surface (Fig. 4 and Fig. S4). In addition, Fig. 4c,e reveal that tectomers adapt to the nanotube curved surface. The successful coating suggests that the oligoglycine assembly can be promoted on the MWCNT-COOH surface in similar fashion to the tectomer assembly reported on mica ${ }^{48}$ or viruses. ${ }^{52,53}$

Electrostatic interactions between the protonated amino terminal groups of oligoglycine and the negative charges of the carboxylic acid groups of the MWCNT-COOH (point of zero charge $\left.\mathrm{pH}_{\mathrm{PZC}} 3.1\right)^{65}$ account for the hybrid formation in water. This kind of interactions is well established in the literature for other carboxylated CNT/peptide systems. ${ }^{66-72}$ In contrast, no electrostatic interaction between the tectomers and pristine CNTs $\left(\mathrm{pH}_{\mathrm{PzC}} 6.6\right)^{65}$ is expected. This lack of interfacial interaction, as observed in Fig. 3, does not allow for the preparation of stable dispersions with non-functionalized CNTs.
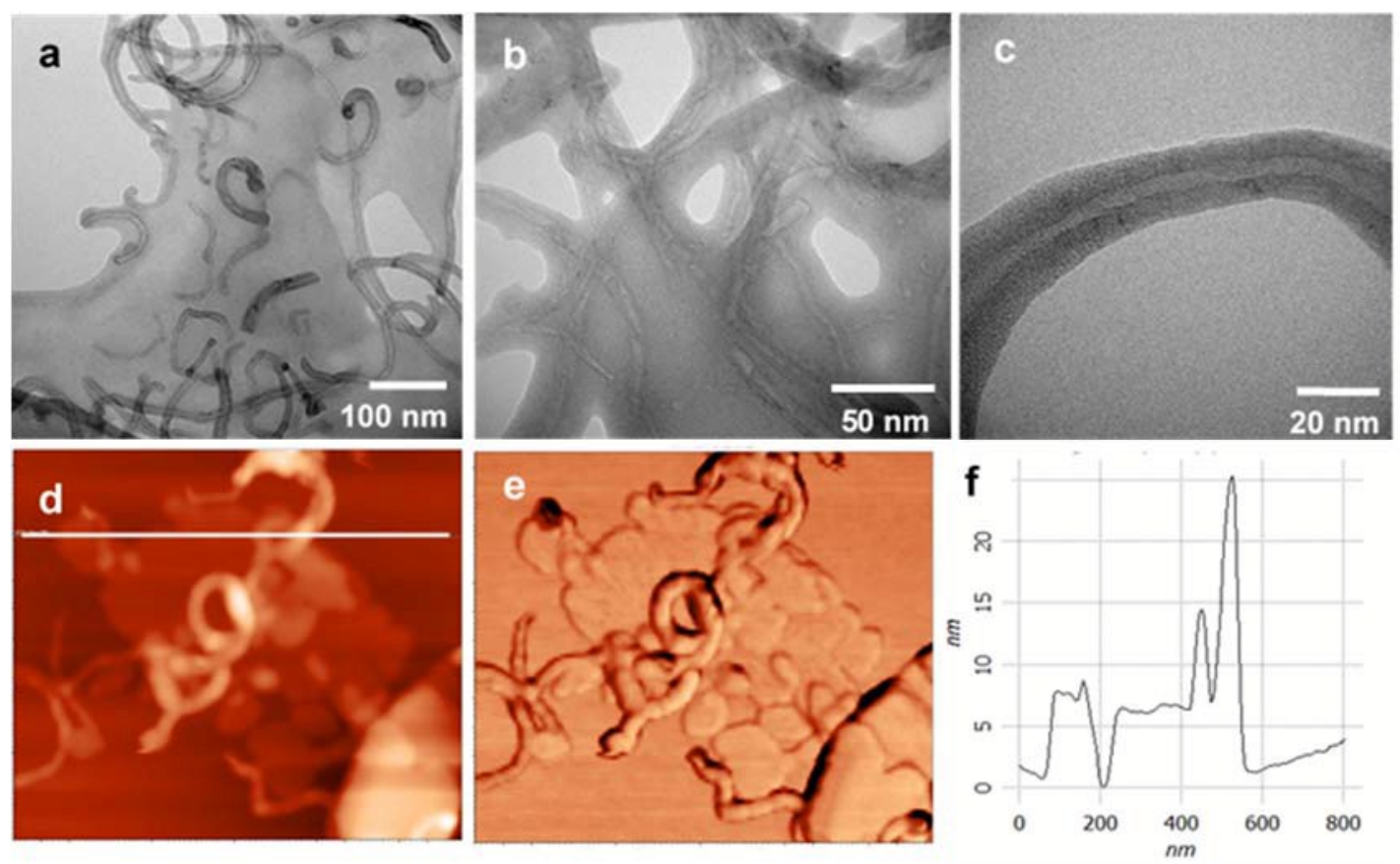

Fig. 4 TEM micrographs of MWCNT-COOH/tectomer hybrids, prepared from $2 \mathrm{~T} 1 \mathrm{mg} \mathrm{mL}^{-1}$ solutions in water (pH 5.6), showing massive peptidic coating of MWCNT-COOH (a-c). AFM topography (d), phase (e), and corresponding line profile (f) of MWCNT-COOH/2T tectomer hybrids deposited on mica. 


\section{PAPER}

Interestingly, the interactions between the tectomer and MWCNT-COOH can be modified by changes in the environmental $\mathrm{pH}$ (Fig. S5). We have explored $\mathrm{pH} \leq 2.2$ and $\mathrm{pH} \geq$ 7.4 to have further evidences of the electrostatic nature of the interactions involved. Upon shifting the $\mathrm{pH}$ value to 2.2 , the tectomer coating disassociates due to the strong protonation of the amino groups in oligoglycine. Additionally, at these low $\mathrm{pH}$ levels, carboxylic groups are not ionized, which yields insoluble MWCNT-COOH. On the other hand, at $\mathrm{pH} 7.4$ there are no favorable electrostatic interactions with the tectomers (most of the amine terminal groups of the tectomers are not protonated), thus no tectomer coating is present on MWCNT$\mathrm{COOH}$. A similar lack of MWCNT-COOH/tectomer interaction was achieved at $\mathrm{pH}$ 12.0. The ability to tune the peptide coating as a function of $\mathrm{pH}$ is very attractive for a variety of applications that require $\mathrm{pH}$-responsive biointerfaces. For example, functionalized CNTs could be controllably released from a $\mathrm{pH}$-dependent peptidic coating upon dissociation at low environmental $\mathrm{pH}$.

A detailed XPS study was performed to gain further insights into the nature of the interaction between CNTs and tectomers. The N1s XPS core level regions are compared in Fig. 5. As only the oligoglycine molecule contains nitrogen, changes in N1s XPS spectra can be interpreted in terms of the interactions established by oligoglycine tectomers with MWCNT-COOH. The peak at binding energy (BE) $\sim 402 \mathrm{eV}$ assigned to protonated amino groups $\left(\mathrm{NH}_{3}^{+}\right)$in the tectomers, disappears in the presence of MWCNT-COOH. This can be explained by the neutralization of the positive charge due to the electrostatic interaction with negatively charged carboxylic groups ( $\mathrm{COO}^{-}$) in MWCNT-COOH. On the other hand, the peak at $\sim 400 \mathrm{eV}$, corresponding to the nitrogen atoms in the oligoglycine antennae, which are involved in hydrogen bonding $(\mathrm{NH} \cdots \mathrm{O}=\mathrm{C})$, is shifted to a higher $\mathrm{BE}$ in the presence of MWCNT-COOH (1.2 eV and $0.8 \mathrm{eV}$ for $2 \mathrm{~T}$ and $4 \mathrm{~T}$, respectively), suggesting partial disruption of the tectomer's hydrogenbonded network. Thus, as it is represented in Fig. 6, electrostatic interactions would be strong enough to induce curvature in the tectomer assemblies, leading to some hydrogen bond breaking. High resolution XPS spectra corresponding to samples of oligoglycines, MWCNT-COOH and hybrids are shown in Fig. S6-S8. For 4T tectomers, hydrogen bonds are formed between the antennae attached to a central carbon (Fig. 1b), which provides restricted mobility and therefore enhanced tectomer structural rigidity. Thus, the interaction with the curved surface of MWCNT-COOH is less favored than for $2 \mathrm{~T}$ tectomers. This is in agreement with the smaller shift observed in the N1s XPS spectra in Fig. 5, which suggests less interaction than in the case of $2 \mathrm{~T}$ tectomers.
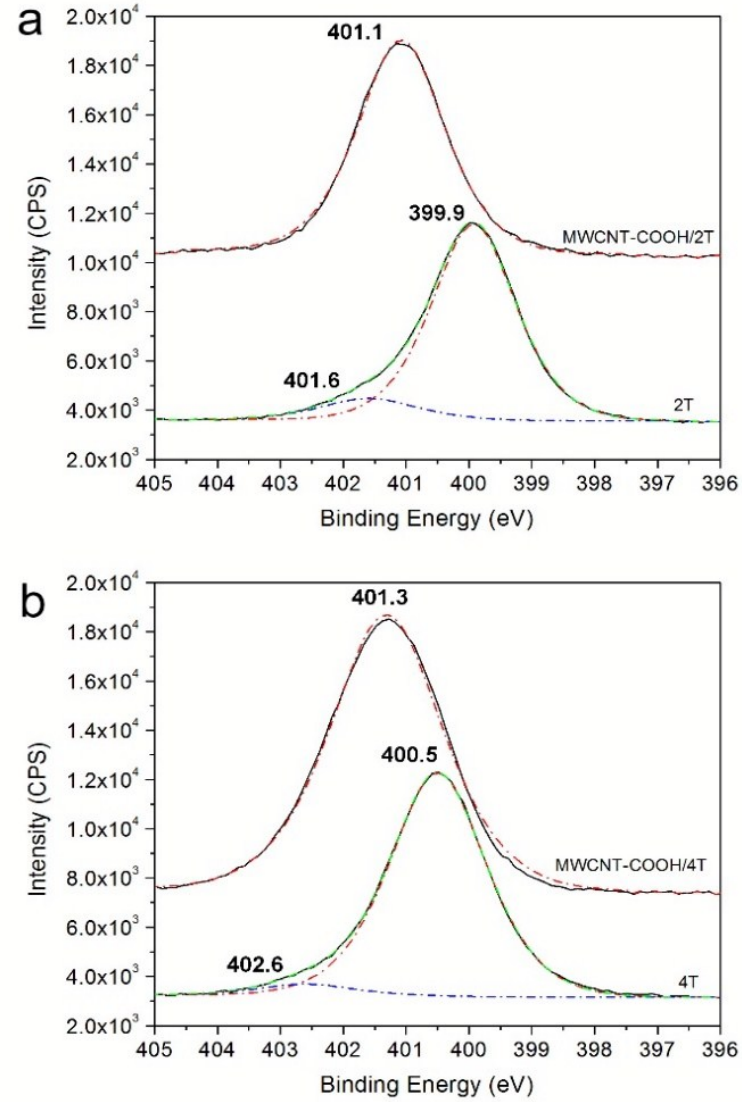

Fig. 5 Comparison of high resolution N1s XPS spectra of (a) 2T and (b) $4 \mathrm{~T}$ and their corresponding hybrids with MWCNT-COOH.

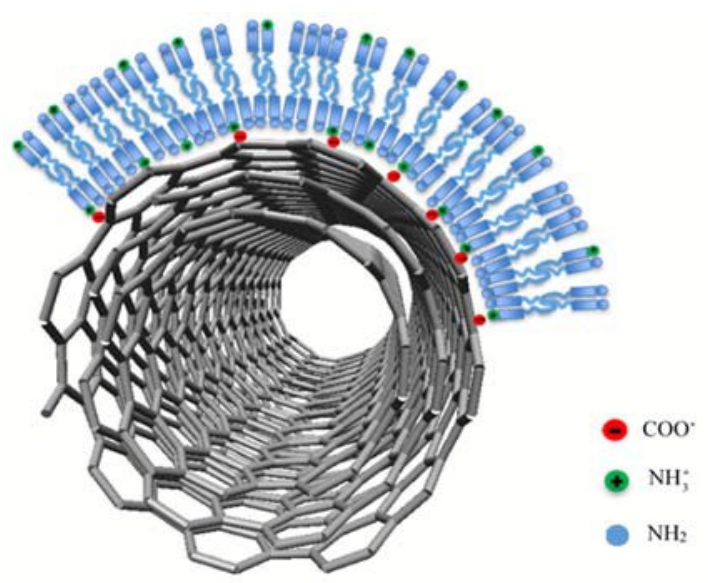

Fig. 6 Schema of MWCNT-COOH/2T tectomer interaction. $\mathrm{COO}^{-}$groups in CNT provides useful anchor sites for tectomers, the electrostatic forces between $\mathrm{NH}_{3}^{+}$and $\mathrm{COO}^{-}$groups being the driving force of hybrid formation. Curvature in the tectomer assembly leads to hydrogen bond breaking, as XPS study suggests. 
We therefore conclude that electrostatic interaction between $\mathrm{NH}_{3}^{+}$and $\mathrm{COO}^{-}$group, is the driving force for MWCNT-COOH/tectomer hybrid formation. This would also explain the lack of interaction of tectomers with nonfunctionalized CNTs (Fig. 3), as well as with MWCNT-COOH at $\mathrm{pH}$ out of the range of values from 3.1 to 7.4 (Fig. S5). Donation of electron density from non-protonated amino groups in tectomers to the $\pi$ system of $\mathrm{CNT}^{73}$ might additionally contribute to the observed shift in the peak at 400 eV in Fig. 5.

$\zeta$-potential provides useful information on changes of the surface charge of nanoparticles after coating procedures. $\zeta$ potential values of $+20.95 \mathrm{mV}$ and $-40.70 \mathrm{mV}$ were obtained for $2 \mathrm{~T}$ and MWCNT-COOH dispersions, respectively, which are related to the presence of protonated terminal amino groups in tectomers and ionized carboxyl groups in MWCNT-COOH. For MWCNT-COOH/2T dispersions, $\zeta$-potential was $+4.42 \mathrm{mV}$ providing further evidence of peptidic coating on MWCNT$\mathrm{COOH}$. 3-potential results, though, should be taken with caution for non-spherical, large aspect ratio particles such as CNTs and tectomers due to the well-known limitations of the Smoluchowski equation. ${ }^{74,75}$

The strong MWCNT-COOH/tectomer interaction has an effect on the water resistance properties of the hybrids. Fig. $7 \mathrm{a}, \mathrm{b}$ compares the effect of water droplet deposition in dropcast MWCNT-COOH and MWCNT-COOH/tectomer coatings on glass substrates. Our results show that only tectomerhybridized coatings remained unaltered.

MWCNT-COOH/tectomer free-standing films on hydrophobic Mitex ${ }^{\mathrm{TM}}$ PTFE filter membranes were prepared by drop casting. The resulting films were then peeled-off from the substrates. The films consist of entangled networks of CNT/tectomer hybrids (Fig. 7c), and side views (Fig. 7d) show the layered structures of these films that resemble those observed in CNT buckypapers ${ }^{76}$ and in graphene-based sheets. ${ }^{77,78}$ The films are electrically conductive $\left(\sim 1 \mathrm{~S} \mathrm{~cm}^{-1}\right)$; the conductivity is comparable to or even higher to those reported in the literature for biocompatible composite materials based on chitosan and CNTs or carbon nanofibers. ${ }^{79-81}$ In the absence of the tectomer binder, the MWCNT-COOH dispersions used do not form free-standing films.

\section{$3.3 \mathrm{GO} /$ tectomer hybrids}

The strong interaction between tectomers and MWCNT-COOH, that led to the successful fabrication of multifunctional hybrids, directed our focus on the fabrication of GO/tectomer hybrids. Combining the 2D structures of both tectomers and $\mathrm{GO}$ is very appealing for a range of applications, in particular for certain bio-applications that require high surface area materials to act as coatings for implants or as scaffold to enhance biocompatibility, mechanical, and other properties. ${ }^{82-}$ 85

Here we investigate the interactions between the tectomers and GO with the intention of achieving GO-based biocomposites. For this study, we used well-exfoliated and

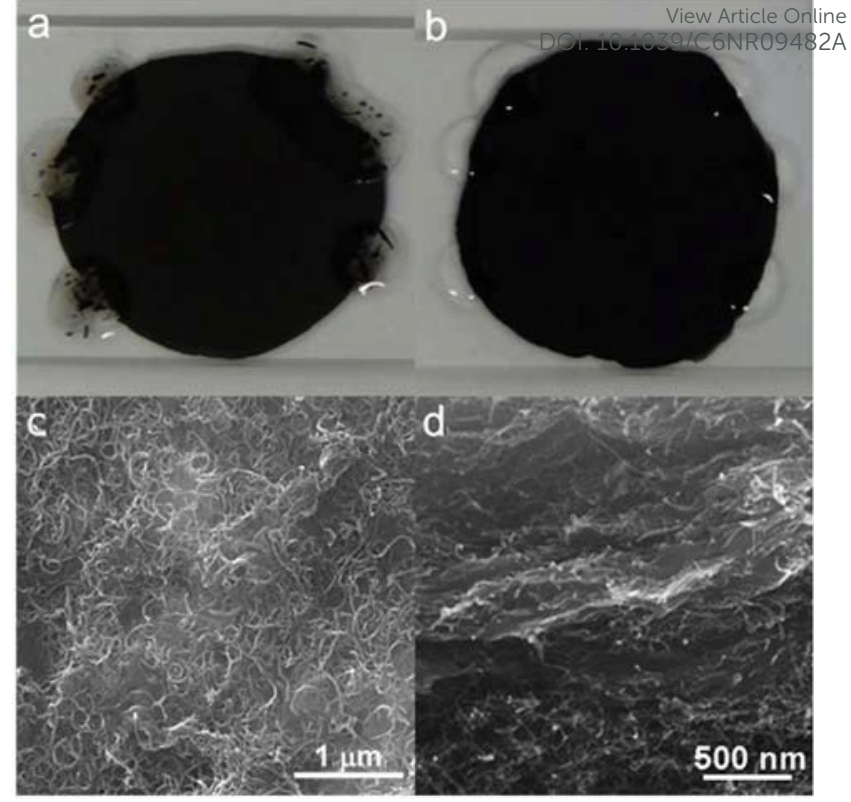

Fig. 7 (a) Image showing that drop-cast MWCNT-COOH films on glass fall apart upon water droplet deposition, but (b) the structure of MWCNT-COOH/2T tectomer coatings remain unaltered. SEM images of free-standing films of MWCNT-COOH/2T tectomer hybrids: (c) top and (d) side views.
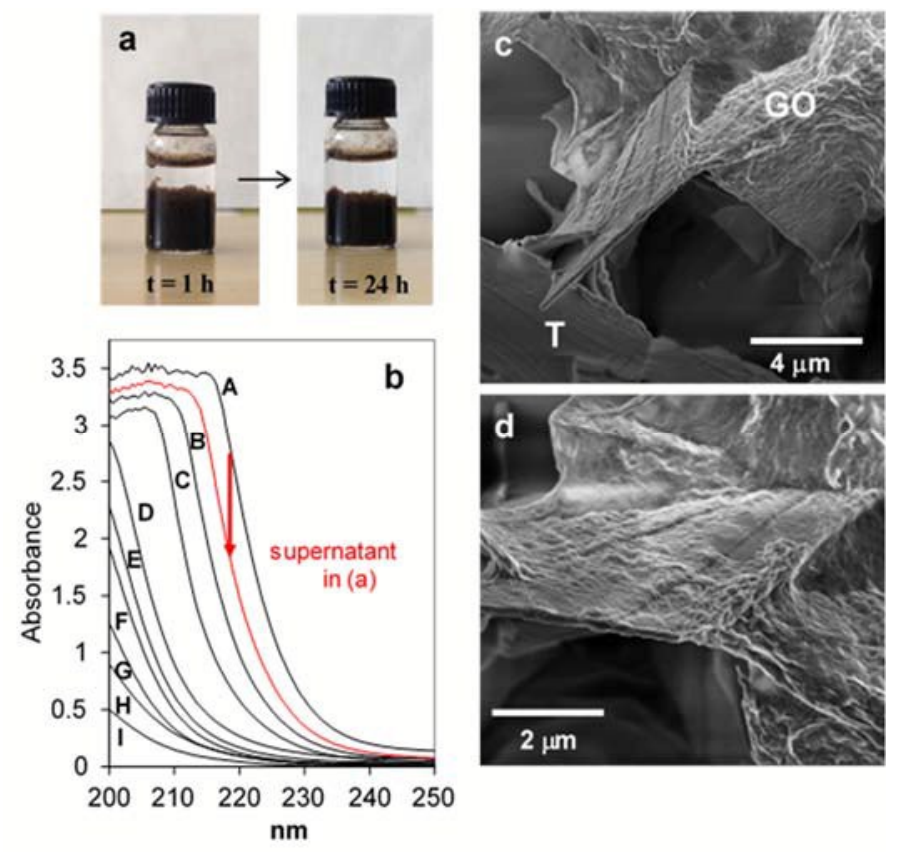

Fig. 8 (a) Pictures of GO sedimentation in water after addition to 2T solution (pH 5.6). (b) Absorption spectra of the supernatant that resulted after $24 \mathrm{~h}$ of sedimentation (-). In order to estimate oligoglycine concentration remaining in the supernatant, spectra corresponding to different solutions of oligoglycine prepared at known concentrations have been included ( $A: 1$, B: 0.4, C: 0.2, D: 0.1, E: 0.07, F: 0.05, G: 0.04, H: 0.02, I: 0.01, H: $0.007 \mathrm{mg} \mathrm{mL}^{-}$ $\left.{ }^{1}\right)$. (c,d) SEM images of the resulting GO/2T tectomer hybrids. T and GO denote tectomer and graphene oxide, respectively. 
stable GO dispersions in water. After addition to the tectomer solution (either $2 \mathrm{~T}$ or $4 \mathrm{~T}$ ), GO instantaneously flocculates, resulting in a colorless supernatant (Fig. 8a, Fig. S9a, and Movie S1). Thus, the results are strikingly different from for MWCNT-COOH. The supernatant can be removed, and the sediment dried to obtain a $\mathrm{GO} /$ tectomer hybrid composite.

SEM characterization of the flocculated GO sediments, after being thoroughly washed with water to remove the non-specifically bound materials, shows extensively coating of highly exfoliated $\mathrm{GO}$ on rigid tectomer platelets (Fig. 8c,d and Fig. S9c,d). Due to the 2D structure of both tectomers and $\mathrm{GO}$, the interfacial interaction per unit area in these hybrids is maximized, leading to the formation of novel, unique multilayered assemblies. UV-vis spectroscopy studies performed on the resulting supernatants provide a quantitative estimation of the amount of oligoglycine involved in the formation of these hybrids during GO sedimentation. From the decrease in intensity in the absorption spectra in Fig. $8 \mathrm{~b}$ and Fig. S9b, we conclude that there is a $40 \%$ decrease in $2 \mathrm{~T}$ molar concentration (60\% in the case of $4 \mathrm{~T})$, as tectomers are removed from solution due to the interfacial interaction established with GO. Efficient GO removal from solution when mixed with oligoglycine solutions is demonstrated when comparing the resulting clear supernatants shown in Fig. 8 and Fig. S9 to pictures of high diluted GO solutions (Fig. S10). Thus, tectomer-assisted flocculation is an ideal way of efficiently recovering $\mathrm{GO}$ flakes from aqueous dispersion without the need of additional flocculation agents.

Tectomers efficiently interact with both MWCNT-COOH and GO. The chemical nature of the interaction with tectomers is, however, different for both carbon nanomaterials: while carboxylic groups in GO are only located at the periphery of the GO structure, epoxyand hydroxyl groups extensively functionalize the basal plane, ${ }^{86-88}$ and are capable of hydrogen bonding formation with the amino terminal groups of tectomers. Actually, strong ionic hydrogen bonds can be formed if amino groups are protonated as $\mathrm{N}^{+}-\mathrm{H} \cdots \mathrm{O} .{ }^{89}$ This has been confirmed by XPS characterization. High resolution XPS spectra of GO and GO/tectomer hybrids are presented in Fig. S11 and S12, respectively, and the corresponding N1s XPS spectra are compared in Fig. 9. All peaks are shifted to lower BE in the $\mathrm{GO} /$ tectomer hybrids, suggesting the donation of electron density from oxygenated groups in GO to tectomer, leading to hydrogen bonding formation. As indicated above, strong ionic hydrogen bonds could be established between $\mathrm{GO}$ and protonated amino groups of tectomers $\left(\mathrm{N}^{+}-\mathrm{H} \cdots \mathrm{O}\right)$ and, consequently, it is observed in the N1s region that the peak at $\sim 402 \mathrm{eV}$, assigned to protonated amino groups, is notably downshifted (0.3 and $1.3 \mathrm{eV}$ for $2 \mathrm{~T}$ and $4 \mathrm{~T}$ tectomer hybrids, respectively) when interacting with $\mathrm{GO}$. The larger shifts in BE of the N1s features when using 4T tectomers further accounts for their stronger interaction with $\mathrm{GO}$.

\subsection{MWCNT-COOH/tectomer hybrid coatings on GO fibers}

Because of the high affinity of tectomers to GO, the next step was to apply pristine tectomer and MWCNT-COOH/tectomer hybrid coatings onto wet-spun GO fibers (Fig. 10a). Tectomer coatings consist of assemblies of non-covalently bound platelets (Fig. 10b).
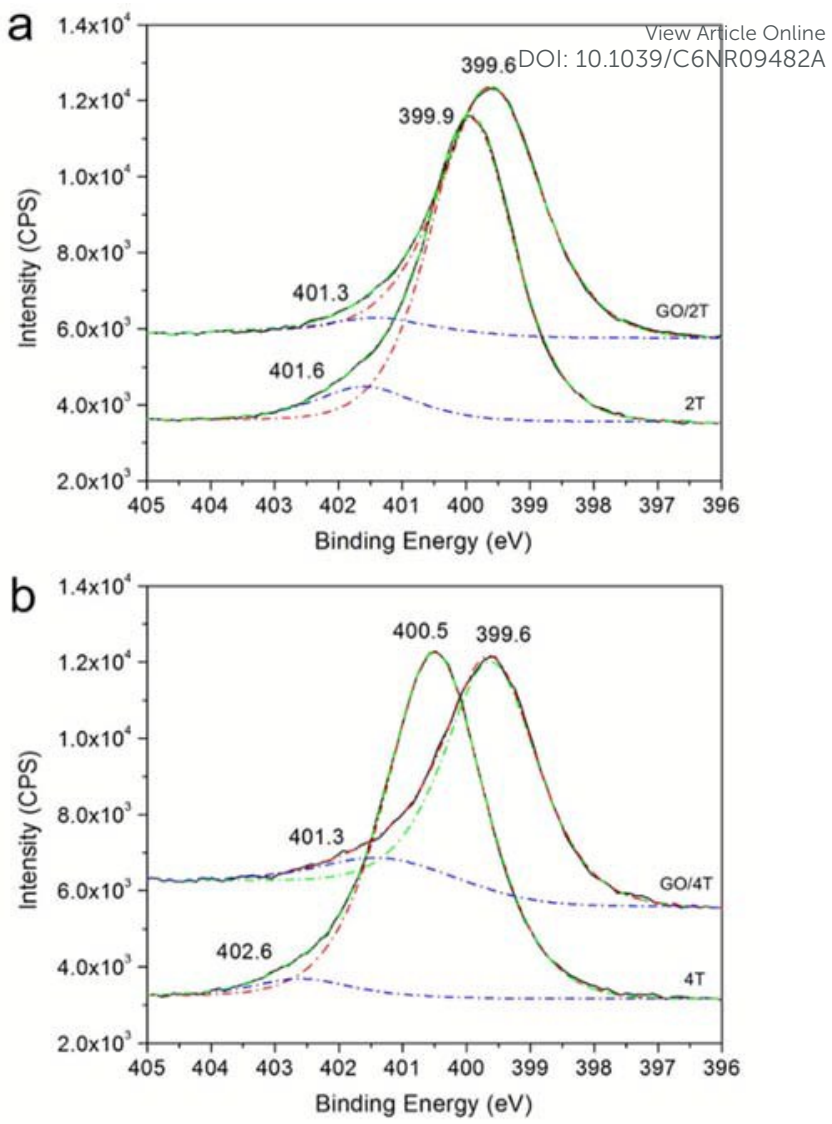

Fig. 9 Comparison of high resolution N1s XPS spectra of (a) 2T, and (b) 4T and their corresponding hybrids with $\mathrm{GO}$.

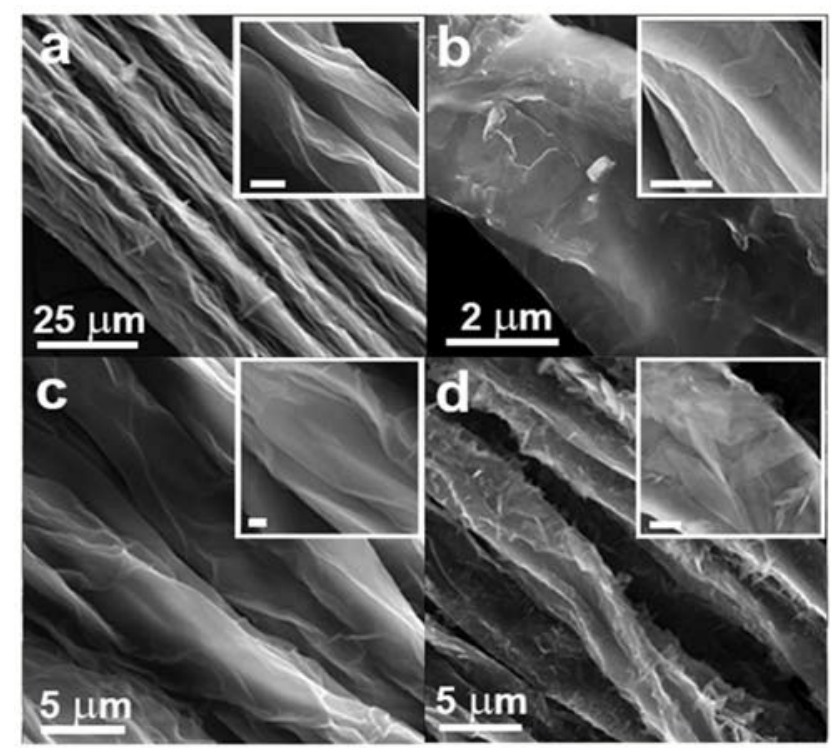

Fig. 10 (a) SEM micrographs of a pristine, uncoated GO fiber, and (b) a GO fiber coated by immersion in $2 \mathrm{~T}$ solution ( $\mathrm{pH} 5.6$ ), after washing procedures used to remove the non-specifically bound materials (see Materials and Methods Section). Results indicate that tectomer coatings are extensively removed upon immersion in buffer $\mathrm{pH} 2.2$ for 3 hours (c), however no tectomer coating removal occurs in buffer $\mathrm{pH} 7.4$ (d). The scale bars in the insets are $500 \mathrm{~nm}$. 
Such coatings are extremely resistant to thorough water washing procedures, but can be successfully removed if coated fibers are immersed in buffer pH 2.2 (Fig. 10c). On the contrary, no tectomer coating removal occurs when immersing the GO/tectomer fibers in buffer $\mathrm{pH} 7.4$ (Fig. 10d), further pointing out that the nature of the interaction between tectomers and GO is different from that between tectomers and MWCNT-COOH.

We also observed that GO fibers easily disassemble and fall apart upon direct immersion in aqueous MWCNT-COOH dispersions, due to the well-known affinity between CNT and GO.90 However, if the fibers are first coated with the tectomer, they can then be subsequently decorated with the MWCNT-COOH (Fig. $11 a, b)$, with the tectomer layer acting like a protective adhesive. MWCNT-COOH/tectomer coatings are also very resistant to long water washing procedures (see Materials and Methods, section 2.2). Alternatively, ultrathin MWCNT- $\mathrm{COOH} /$ tectomer coatings can be fabricated by directly immersing GO fibers in MWCNT$\mathrm{COOH} /$ tectomer solutions (Fig. 11c,d). Certainly, thick CNT coatings can be achieved through multi-impregnation processes (Fig. S13).

The simple procedure for CNT functionalization of GO fibers described here can be considered as an alternative approach to other strategies for CNT functionalization/coating of substrates (including chemical vapour deposition techniques, ${ }^{91-94}$ substrate transfer/printing, ${ }^{95}$ the use of magnetic fields, ${ }^{96}$ electrophoresis, ${ }^{97,98}$ and other substrate chemical functionalization routes ${ }^{99}$ ), and may not be restricted to GO-based surfaces. These CNT/tectomer coatings are promising in nanoelectronics, sensor applications, catalysis, biocompatible CNT inks, cell culture and smart textile

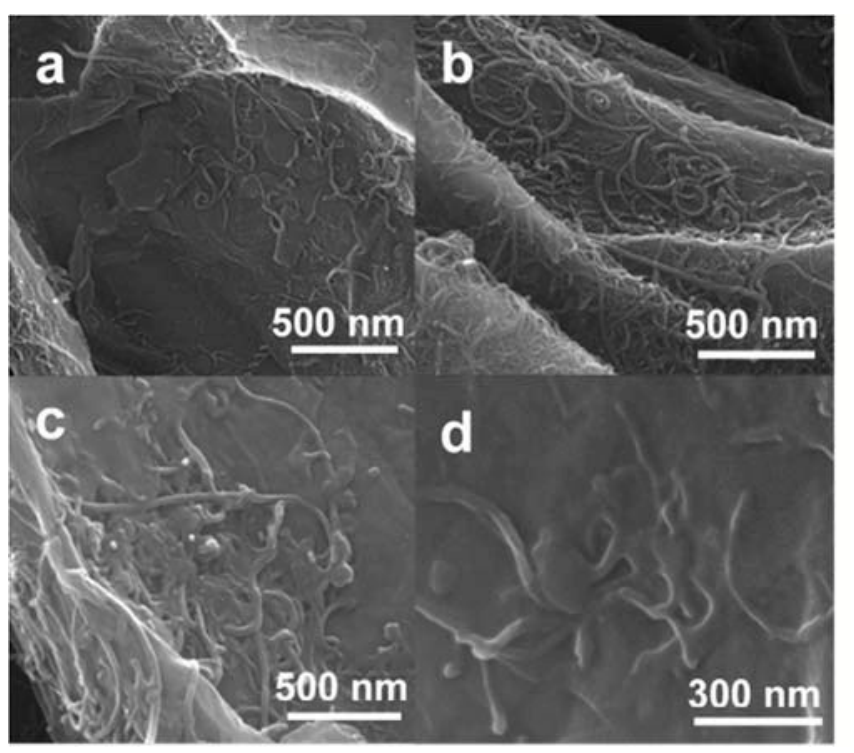

Fig. $11(a, b)$ SEM micrographs of a GO fiber coated in two steps, first by immersion in $2 \mathrm{~T}$ solution ( $\mathrm{pH} 5.6)$ and then in MWCNT-COOH solution, and (c,d) a GO fiber coated in one step by immersion in a MWCNT-COOH/2T solution. Washing procedures were performed to remove the nonspecifically bound materials (see Materials and Methods section). applications. These peptide functionalized GO fibers may

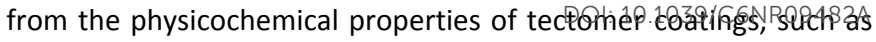
their successful binding to viruses and bacteria, ${ }^{50-53}$ as well as their nanocarrier for drug delivery and phase transfer functionalities. ${ }^{55}$ This, combined with the GO fiber's knittability, ${ }^{58}$ make these tectomer functionalized fibers attractive for smart bio-textile applications. Textile-based synthetic scaffolds possess excellent surface-to-volume ratio of fibers offering a huge area for cell adhesion. Additionally, the porosity of the textiles can be easily modulated at different length-scales.

\subsection{Tectomer-based hybrids for bio-scaffolds}

Tissue engineering tumour models are of great importance for studying ex vivo the tumour development and response to treatment. However, due to the complexity of the tumour microenvironment, building accurate in vitro tumour models for more effective research and evaluation of the potential therapeutic targets remains a challenge. ${ }^{100,101}$ As proof-of-concept, in order to show that the hybrid materials reported here can act as scaffoldbased tissue engineered constructs, pancreatic cancer cells were seeded on both pristine tectomer and MWCNT-COOH/tectomer scaffolds. We plated three types of pancreatic cell lines (PANC-1, BxPC-3 and AsPC-1, Fig. S14), and monitored the cell growth via cell viability assays. All three pancreatic cell lines represent the pancreatic ductal adenocarcinoma, which is the most common cancer of the pancreas in humans. ${ }^{102}$ PANC-1 and BxPC-3 are derived from a primary tumour, and AsPC-1 originates from ascites (metastasis). ${ }^{103}$ Each cell line has an epithelial morphology and the adherent cells form a monolayer in culture. As can be seen in Fig. $12 \mathrm{a}-\mathrm{c}$, the cell viability on $2 \mathrm{D}$ pristine $2 \mathrm{~T}$ tectomer and tectomer/MWCNT-COOH hybrid scaffolds remains high for all cell lines. For AsPC-1 cell line in particular, the cell viability on $2 \mathrm{D}$ pristine tectomer and tectomer/MWCNT-COOH films is as high as the control (Fig. 12c). Nevertheless, for all cell lines under study, there is a significant reduction of the cell growth on the pristine MWCNT-COOH substrates in the absence of tectomer. This reduction is more pronounced for PANC- 1 and BxPC- 3 cell lines and it is less for AsPC-1 cell line. However, it is evident that for all cell lines under study the presence of the tectomer stimulates cell growth. Similar cell culture results have been achieved for $4 \mathrm{~T}$ (Fig. S15). In these cell culture tests, the MWCNT-COOH/tectomer films were stably attached to the bottom of the plates, allowing the pancreatic cells to grow and it was verified that these films did not fall apart or degrade during the whole culture period. Fig. S16a,b shows that the drop-cast MWCNT- $\mathrm{COOH} /$ tectomer films remain unaltered upon buffer $\mathrm{pH} 7.4$ or cell culture medium $\mathrm{pH}$ 7.0-7.6 droplet deposition.

In addition, SEM characterization of $\mathrm{GO}$ fibers coated by MWCNT-COOH/tectomer hybrids shows that the hybrids are not detached from the $\mathrm{GO}$ fibers after immersion in buffer $\mathrm{pH} 7.4$ or cell culture medium pH 7.0-7.6 for 3 days (Fig. S16c-f). As shown in Fig. $12 \mathrm{~d}, \mathrm{e}$, pancreatic cancer cell lines (PANC-1 cells in particular in this figure) efficiently attach to the GO fibers covered with pristine tectomers and tectomer/MWCNT-COOH hybrid coatings. Furthermore, the GO fibers can provide a 3D-like environment for the cells to grow, as they can be incorporated into higher order 
Nanoscale
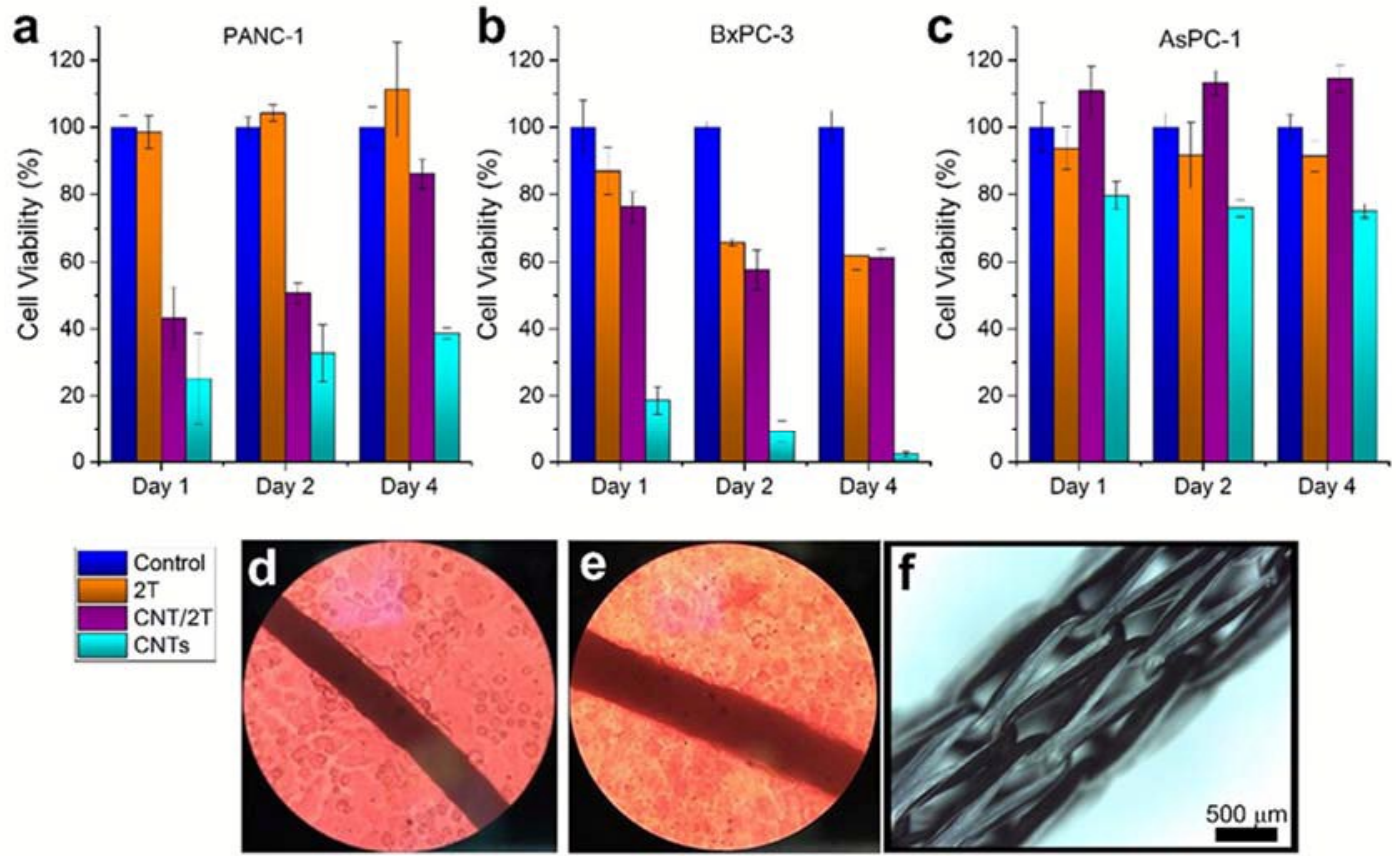

Fig. 12 Cell growth on $2 \mathrm{~T}$ tectomer, pristine MWCNT-COOH, MWCNT-COOH/2T scaffolds and controls for different pancreatic cancer cell lines: (a) PANC-1, (b) BxPC-3 and (c) AsPC-1. Optical microscope images of GO fiber coated with (d) $2 \mathrm{~T}$ and (e) MWCNT-COOH/2T, showing successful attachment of PANC-1 cells to the fibers after 3 days of culture. (f) Optical micrograph of knitted $G O$ fibers showing potential of these scaffolds to support 3D growth of cells.

textile structures (Fig. 12f). The latter is of importance in tissue engineering as it can provide a 3D environment which can enhance cell-cell interactions, which is critical for cancer screening studies.

\subsection{Discussion of potential applications of hybrid composites and coatings}

The use of amino-terminated oligoglycines offers attractive biofunctionalization to carbon nanomaterials. The interaction of tectomers with CNTs can be suitably controlled by adjusting the $\mathrm{pH}$, therefore opening interesting avenues toward applications for the $\mathrm{CNT} /$ tectomer hybrids. This kind of conducting bio-nanocomposites with enhanced hydrophobicity coupling protective and adhesive functionalities offer remarkable features, for example, for technological coatings, nanoelectronics, biocompatible CNT inks and smart textile applications. From the bio-applications point of view, $\mathrm{pH}$-responsive CNT/tectomer interaction could be potentially used for the development of CNT-based devices such as biosensors, where tectomer coatings would additionally provide a $\mathrm{pH}$-sensitive biointerface to CNT networks and electrodes. CNT/tectomer hybrids might also be of particular interest for controlled release of therapeutic and diagnostic agents, exploiting the cell penetrating capabilities of functionalized CNTs. ${ }^{5,104-106}$ It is known that tumoral tissues have a more acidic environment compared to healthy tissues. ${ }^{107,108}$ As assembly/disassembly of tectomers is highly sensitive to $\mathrm{pH}$ modulation, these hybrids are promising candidates for site-specific controlled delivery of anticancer drugs.

Tectomers can be used as biointerfaces for GO-based materials with potential applications as scaffolds for CNT immobilization. ${ }^{80,109-}$ 112 Thus, the GO fiber impregnation strategy described here is very appealing for the fabrication of functional bio-coatings whose physicochemical properties could be suitably tuned by controlling the density, structural and chemical features of the attached CNT materials.

Hybrid materials, as described in the present paper, possess very broad application potential for tissue engineering. The characteristics of CNTs are particularly relevant, owing to the fact 
that their size resembles collagen protein at the nanoscale level, thus mimicking the nano-architecture of the extra cellular matrix (ECM). ${ }^{113}$ The hybrids can be made into $2 \mathrm{D}$ scaffolds by vacuum filtration, spin-coating, drop-casting, etc., providing versatile and tunable scaffold characteristics. Most importantly, such hybrids can also be used to coat the inner structure of highly porous, high surface area polymeric scaffolds or the surface of GO fibers providing the necessary nanoscale topography with 3D architecture required for the efficient adsorption of cell-mediating molecules. However, CNTs without the surface modification can induce an immune response. Tectomer functionalization is simple and noninvasive, and eludes the need for the synthesis of peptides with specific chemical linkages, which could alter peptide functionality. On the other hand, as we have shown in the present work, tectomer hybrids could be used for scaffolds to engineer 'ideal tumours' as an ex vivo approach to study cancer. Furthermore, $\mathrm{CNT} /$ tectomer films are electrically conductive $\left(\sim 1 \mathrm{~S} \mathrm{~cm}^{-1}\right)$. Such electrical conductivity is sufficient to support electrical stimulation of cell-tissue constructs. Therefore, MWCNT-COOH/tectomer hybrids could potentially be used as scaffolds for cardiac tissue engineering. ${ }^{80,81,114}$

\section{Conclusions}

The self-assembly capabilities of amino-terminated oligoglycines into $2 \mathrm{D}$ tectomer structures enabled the development of novel $\mathrm{pH}$ responsive, ultrathin hybrid composites and coatings of MWCNT$\mathrm{COOH}$ and $\mathrm{GO} /$ tectomers. MWCNT-COOH/tectomer hybrids form stable inks and can be engineered in the form of conductive films. We showed that the driving force for the formation of MWCNT$\mathrm{COOH} /$ tectomer hybrids is the electrostatic interaction between the negatively charged carboxylic groups of MWCNT and the positively charged protonated amino terminal groups of the tectomers. The interaction of tectomers with GO, however, led to the formation of non-soluble GO/tectomer hybrids. We showed that hydrogen bonding formation between the amino terminal groups of tectomers and the oxygen functional groups of $\mathrm{GO}$ accounts for the strong interfacial interaction between both 2D nanomaterials. We provide evidence that the different structural features of CNTs and GO significantly affect their interaction with $2 \mathrm{~T}$ and $4 \mathrm{~T}$ tectomers. Thus, the interaction with the curved surface of MWCNT-COOH is less favored for $4 \mathrm{~T}$ than for $2 \mathrm{~T}$ tectomers, due to the higher structural rigidity of $4 \mathrm{~T}$ tectomers. On the contrary, in the case of $\mathrm{GO}$, stronger interaction with $\mathrm{GO}$ occurs for $4 \mathrm{~T}$ than for $2 \mathrm{~T}$ tectomers. Modulation of the solution $\mathrm{pH}$ enabled us to obtain coated and uncoated carbon materials on demand. We have exploited the large affinity of tectomers for both MWCNT-COOH and GO to coat wet-spun GO fibers with MWCNT-COOH using tectomers as bioadhesive. Tectomer coatings can provide enhanced hydrophobicity and water resistant properties against CNT film dissociation. The hybrid materials reported here can act as biocompatible scaffold-based engineered constructs.

A plethora of novel functional bio-materials can be envisioned by further exploring the $\mathrm{pH}$-dependant features of these hybrids and assemblies, wettability properties, as well as the versatile chemical functionalization of CNT, GO and oligoglycine. In particular, the strong $\mathrm{GO} /$ tectomer interaction and Atheir $2 \mathrm{P}$ structures are very appealing for the use of the Hybrads/as 5 plateotions for biodevices. This could allow for the tuning of physicochemical properties along with their integration into biological environments, which may be very attractive for a range of technological and biomedical applications.

\section{Acknowledgements}

Authors thank the Fundación Domingo Martínez (Ayudas a la Investigación 2013), the Spanish Ministerio de Economía y Competitividad MINECO (Plan Nacional de I+D+I, Project CTQ2012035535), DGA (Grupo Consolidado de Investigación Aplicada ref T08), CSIC Intramural Entorno Project, JMR ARC Future Fellowship (FT130100380), Engineering and Physical Sciences Research Council (EPSRC) grant no. EP/K031562, University of Sussex Strategic Development Fund, H2020-MSCA-ITN-2014 Enabling Excellence project, and the College of Applied Medical Sciences Research Center and the Deanship of Scientific Research at King Saud University for supporting this research. The TEM, and ESEM microscopy work has been conducted in the "Laboratorio de Microscopías Avanzadas" at "Instituto de Nanociencia de Aragón Universidad de Zaragoza". The authors acknowledge the LMA-INA for offering access to their instruments and expertise. Contact angle measurements have been performed in the Nanoquim Platform Laboratory at Institut de Ciència de Materials de Barcelona (ICMABCSIC). The authors thank Alfonso Ibarra, Rodrigo FernándezPacheco, Carlos Cuestas Ayllón, Neus Romà, José María Montenegro, John R. Pearson and Elvira Aylón for valuable technical support and fruitful discussions. The authors declare no competing financial interest.

\section{References}

1 W.-J. Jeong, S.-J. Choi, J. S. Choi and Y.-B. Lim, ACS Nano, 2013, 7, 6850-6857.

2 M. S. Spector, A. Singh, P. B. Messersmith, and J. M. Schnur, Nano Lett, 2001, 1, 375-378.

3 L. Liu, K. Busuttil, S. Zhang, Y. Yang, C. Wang, F. Besenbacher and M. Dong, Phys Chem Chem Phys, 2011, 13, 17435-17444.

4 K. Sakakibara, J. P. Hill and K. Ariga, Small, 2011, 7, 12881308.

5 E. Heister, E. W. Brunner, G. R. Dieckmann, I. Jurewicz and A. B. Dalton, ACS Appl Mater Interfaces, 2013, 5, 1870-1891.

6 L. Zhang, T. Wang, Z. Shen and M. Liu, Adv Mater, 2016, 28, 1044-1059.

7 A. Sorrenti, O. Illa and R. M. Ortuño, Chem Soc Rev, 2013, 42, 8200-8219.

8 X. Zhao, Y. Liu, J. Lu, J. Zhou and J. Li, Chem Eur J, 2012, 18, 3687-3694.

9 Y. Wan, G. Liu, X. Zhu and Y. Su, Chem Central J, 2013, 7, 14.

10 B. Dinesh, M. A. Squillaci, C. Ménard-Moyon, P. Samori, and A. Bianco, Nanoscale, 2015, 7, 15873-15879.

11 E. Muñoz, D. Coutinho, R. F. Reidy, A. Zakhidov, W. Zhou and K. J. Balkus Jr., Micropor Mesopor Mater, 2004, 67, 61-65.

12 N. Numata, M. Asai, K. Kaneko, T. Hasegawa, N. Fujita, Y. Kitada, K. Sakurai and S. Shinkai, Chem Lett, 2004, 33, 232 233.

13 M. Zheng, A. Jagota, M. S. Strano, A. P. Santos, P. Barone, S. G. Chou, B. A. Diner, M. S. Dresselhaus, R. S. McLean, G. B. 
Onoa, G. G. Samsonidze, E. D. Semke, M. Usrey and D. J. Walls, Science, 2003, 302, 1545-1548.

14 H. Cathcart, S. Quinn, V. Nicolosi, J. M. Kelly, W. J. Blau and J. N. Coleman, J Phys Chem C, 2006, 111, 66-74.

15 X. Gong, A. K. Sharma, M. S. Strano and D. Mukhopadhyay, ACS Nano, 2014, 8, 9126-9136.

16 R. A. MacDonald, B. F. Laurenzi, G. Viswanathan, P. M. Ajayan and J. P. Stegemann, J Biomed Mater Res A, 2005, 74, 489-496.

17 D. Movia, A. Prina-Mello, D. Bazou, Y. Volkov and S. Giordani, ACS Nano, 2011, 5, 9278-9290.

18 Q. Yang, Z. Wang and J. Weng, Soft Matter, 2012, 8, 98559863.

19 C. Cheng, S. Li, S. Nie, W. Zhao, H. Yang, S. Sun and C. Zhao, Biomacromolecules, 2012, 13, 4236-4246.

20 S. Srinivasan, S. S. Babu, V. K. Praveen and A. Ajayaghosh, Angew Chem Int Ed, 2008, 47, 5746-5749.

21 S. Srinivasan, V. K. Praveen, R. Philip and A. Ajayaghosh, Angew Chem Int Ed, 2008, 47, 5750-5754.

22 B. Vedhanarayanan, V. S. Nair, V. C. Nair and A. Ajayaghosh, Angew Chem, 2016, 128, 10501-10505.

23 P. Choudhury, D. Mandal, S. Brahmachari and P. K. Das, Chem Eur J, 2016, 22, 5160-5172.

24 T. Thomas, R. J. Mascarenhas, B. E. K. Swamy, P. Martis, Z. Mekhalif and B. S. Sherigara, Colloids Surf B, 2013, 110, 458465.

25 A. Star, J.-C. P. Gabriel, K. Bradley and G. Grüner, Nano Lett, 2003, 3, 459-463.

26 D. R. Samarajeewa, G. R. Dieckmann, S. O. Nielsen and I. H. Musselman, Nanoscale, 2012, 4, 4544.

27 W. Nakanishi, K. Minami, L. K. Shrestha, Q. Li, J. P. Hill and K. Ariga, Nano Today, 2014, 9, 378-394.

28 J. López-Andarias, J. L. López, C. Atienza, F. G. Brunetti, C. Romero-Nieto, D. M. Guldi and N. Martín, Nature Comm 2014, 5, 3763.

29 S. Marchesan and M. Prato, Chem Comm, 2015, 51, 4347 4359.

30 T. Fujigaya and N. Nakashima, Sci Technol Adv Mater, 2015, 16, 024802

31 G. R. Dieckmann, A. B. Dalton, P. A. Johnson, J. Razal, J. Chen, G. M. Giordano, E. Muñoz, I. H. Musselman, R. H. Baughman, and R. K. Draper, J Am Chem Soc, 2003, 125, 1770-1777.

32 V. Nicolosi, H. Cathcart, A. B. Dalton, D. Aherne, G. R. Dieckmann and J. N. Coleman, Biomacromolecules, 2008, 9, 598-602.

33 H. Xie, E. J. Becraft, R. H. Baughman, A. B. Dalton and G. R. Dieckmann, J Pep Sci, 2008, 14, 139-151.

34 C. G. Salzmann, M. A. H. Ward, R. M. J. Jacobs, G. Tobias, M. L. H. Green, J Phys Chem C, 2007, 111, 18520-18524.

35 E. Muñoz, A. Sreelatha, R. Garriga, R. H. Baughman and W. J. Goux, J Phys Chem. B, 2013, 117, 7593-7604.

36 Y.-C. Lin and S.-W. Kuo, J Pol Sci A, 2014, 52, 321-329.

$37 \mathrm{H}$. Xie, A. Ortiz-Acevedo, V. Zorbas, R. H. Baughman, R. K. Draper, I. H. Musselman, I. H., A. B. Dalton and G. R. Dieckmann, J Mater Chem, 2005, 15, 1734-1741.

38 A. B. Dalton, A. Ortiz-Acevedo, V. Zorbas, E. Brunner, W. M. Sampson, S. Collins, J. M. Razal, M. Miki Yoshida, R. H. Baughman, R. K. Draper, I. H. Musselman, M. Jose-Yacaman and G. R. Dieckmann, Adv Funct Mater, 2004, 14, 1147-1151.

39 M. Numata, K. Sugikawa, K. Kaneko and S. Shinkai, Chem Eur $J, 2008,14,2398-2402$.

40 G. Grigoryan, Y. H. Kim, R. Acharya, K. Axelrod, R. M. Jain, L. Willis, M. Drndic, J. M. Kikkawa and W. F. DeGrado, Science, 2011, 332, 1071-1076.

41 M. in het Panhuis, S. Gowrisanker, D. J. Vanesko, C. A. Mire, H. Jin, H. Xie, R. H. Baughman, I. H. Musselman, B. E. Gnade, G. R. Dieckmann and R. K. Draper. Small, 2005, 1, 820-823.
42 L. Zheng, D. Jain and P. Burke, J Phys Chem C, 2009 , 113 3978-3985.

DOI: 10.1039/C6NR09482A

43 Z. Kuang, S. N. Kim, W. J. Crookes-Goodson, B. L. Farmer and R. R. Naik, ACS Nano, 2010, 4, 452-458.

44 T. C. Holmes, Trends Biotechnol, 2002, 20, 16-21.

45 K. H. Chan, S. Zhuo and M. Ni, OA Tissue Engineering, 2013, 1,6 .

46 S. Maude, E. Ingham and A. Aggeli, Nanomedicine, 2013, 8, 823-847.

47 M. Perán, M. A. García, E. López-Ruiz, M. Bustamante, G. Jiménez, R. Madeddu and J. A. Marchal, Int J Mol Sci, 2012, 13, 3847-3886.

48 S. V. Tsygankova, A. A. Chinarev, A. B. Tuzikov, I. S. Zaitsev, N. Severin, A. A. Kalachev, J. P. Rabe and N. V. Bovin, J Biomater Nanobiotech, 2011, 2, 91-97.

49 S. V. Tsygankova, A. A. Chinarev, A. B. Tuzikov, N. Severin, A. A. Kalachev, J. P. Rabe, A. S. Gambaryan and N. V. Bovin, Beilstein J Org Chem, 2014, 10, 1372-1382.

50 N. V. Bovin, A. B. Tuzikov and A. A. Chinarev, Nanotech. Russia, 2008, 3, 291-302.

51 A. Y. Gyurova, S. V. Stoyanov and E. Mileva, Colloids Surf A, 2014, 460, 130-136.

52 A. B. Tuzikov, A. A. Chinarev, A. S. Gambaryan, V. A. Oleinikov, D. V. Klinov, N. B. Matsko, V. A. Kadykov, M. A. Ermishov, I. V. Demin, V. V. Demin, P. D. Rye and N. V. Bovin, ChemBioChem, 2003, 4, 147-154.

53 N. V. Bovin, A. B. Tuzikov, A. A. Chinarev, A. S. Gambaryan, Glycoconjugate J, 2004, 21, 471-478.

54 A. Almasian, N. M. Mahmoodi and M. E. Olya, J Ind Eng Chem, 2015, 32, 85-98.

55 R. Garriga, I. Jurewicz, E. Romero, C. Jarne, V. L. Cebolla, A. B. Dalton and E. Muñoz, ACS Appl Mater Interfaces, 2016, 8, 1913-1921.

56 M. Kogiso, S. Ohnishi, K. Yase, M. Masuda and T. Shimizu, Langmuir, 1998, 14, 4978-4986.

57 N. Nuraje, H. Bai and K. Su, Prog Polym Sci, 2013, 38, 302343.

58 S. Seyedin, M. S. Romano, A. I. Minett and J. M. Razal, Sci Reports, 2015, 5, 14946.

59 J. N. Coleman, M. Lotya, A. O'Neill, S. D. Bergin, P. J. King, U. Khan, K. Young, A. Gaucher, S. De, R. J. Smith, I. V. Shvets, S. K. Arora, G. Stanton, H. Y. Kim, K. Lee, G. T. Kim, G. S. Duesberg, T. Hallam, J. J. Boland, J. J. Wang, J. F. Donegan, J. C. Grunlan, G. Moriarty, A. Shmeliov, R. J. Nicholls, J. M. Perkins, E. M. Grieveson, K. Theuwissen, D. W. McComb, P. D. Nellist and V. Nicolosi, Science, 2011, 331, 568-571.

60 V. Nicolosi, M. Chhowalla, M. G. Kanatzidis, M. S. Strano, J. N. Coleman, Science, 2013, 340, 1226419.

61 H. Lee, S. H. Son, R. Sharma and Y.-Y. Won, J Phys Chem B, 2011, 115, 844-860.

62 J. Suh, H.-J. Paik and B. K. Hwang, Bioorg Chem, 1994, 22, 318-327.

63 D. J. Belton, S. V. Patwardhan, V. V. Annenkov, E. N. Danilovtseva and C. C. Perry, PNAS, 2008, 105, 5963-5968.

64 R. H. Baughman, A. A. Zakhidov and W. A. de Heer, Science, 2002, 297, 787-792.

65 M. A. Atieh, O. Y. Bakather, B. Al-Tawbini, A. A. Bukhari, F. A. Abuilaiwi and M. B. Fettouhi, Bioinorg Chem Appl, 2010, 603978.

66 N. W. S. Kam and H. Dai, J. Am. Chem. Soc., 2005, 127, 60216026.

67 Q. Mu, W. Liu, Y. Xing, H. Zhou, Z. Li, Y. Zhang, L. Ji, F. Wang, Z. Si, B. Zhang and B. Yan, J Phys Chem C, 2008, 112, 33003307.

68 S. Marchesan and M. Prato, Chem. Comm., 2015, 51, 4347 4359.

69 S. F. Oliveira, G. Bisker, N. A. Bakh, S. L. Gibbs, M. P. Landry and M. S. Strano, Carbon, 2015, 95, 767-779. 
70 X. Zhao, D. Lu, F. Hao and R. Liu, J Hazardous Mater, 2015, 292, 98-107.

71 X. Zhao, F. Hao, D. Lu, W. Liu, Q. Zhou and G. Jiang, ACS Appl. Mater. Interfaces, 2015, 7, 18880-18890.

72 I. Jha and P. Venkatesu, J Phys Chem C, 2016, 120, 1543615445.

73 D. Chattopadhyay, I. Galeska and F. A. Papadimitrakopoulos, J Am Chem Soc, 2003, 125, 3370-3375.

74 B. White, S. Banerjee, S. O'Brien, N. J. Turro and I. P. Herman, J Phys Chem C, 2007, 111, 13684-13690.

75 S. Park, N. Sinha and K. Hamad-Schifferli, Langmuir, 2010, 26, 13071-13075.

76 G. M. Spinks, G. G. Wallace, L. S. Fifield, L. R. Dalton, A. Mazzoldi, D. De Rossi, I. I. Khayrullin and R. H. Baughman, Adv Mater, 2002, 14, 1728-1732.

77 D. A. Dikin, S. Stankovich, E. J. Zimney, R. D. Piner, G. H. B. Dommett, G. Evmenenko, S. T. Nguyen and R. S. Ruoff, Nature, 2007, 448, 457-460.

78 H. Chen, M. B. Müller, K. J. Gilmore, G. G. Wallace, and D. Li, Adv Mater, 2008, 20, 3557-3561.

79 C. Lau, M. J. Cooney and P. Atanassov, Langmuir, 2008, 24, 7004-7010.

80 S. Pok, F. Vitale, S. L. Eichmann, O. M. Benavides, M. Pasquali and J. G. Jacot, ACS Nano, 2014, 8, 9822-9832.

81 A. M. Martins, G. Eng, S. G. Caridade, J. F. Mano, R. L. Reis and G. Vunjak-Novakovic, G. Biomacromolecules, 2014, 15, 635-643.

82 C. Zhao, X. Lu, C. Zanden, and J. Liu, Biomed Mater, 2015, 10, 015019.

83 D. Depan and R. D. Misra, Acta Biomater, 2013, 9, 60846094.

84 J. Kim, Y. R. Kim, Y. Kim, K. T. Lim, H. Seonwoo, S. Park, S. P. Cho, B. H. Hong, P. H. Choung, T. D. Chung, Y. H. Choung and J. H. Chung, J Mater Chem B, 2013, 1, 933-938.

85 D. Depan, B. Girase, J. S. Shah and R. D. Misra, Acta Biomater, 2011, 7, 3432-3445.

86 F. Perozzi, S. Prezioso and L. Ottaviano, J Phys Condens Matter, 2015, 27, 013002.

87 D. R. Dreyer, S. Park, C. W. Bielawski and R. S. Ruoff, Chem Soc Rev, 2010, 39, 228-240.

88 J. Kim, L. J. Cote, F. Kim, W. Yuan, K. R. Shull, J. Huang, J Am Chem Soc, 2010, 132, 8190-8196.

89 M. Meot-Ner, Chem Rev, 2012, 112, PR22-PR103.

90 J.-J. Shao, W. Lv, Q. Guo, C. Zhang, Q. Xu, Q.-H. Yang and F. Kang, Chem Commun, 2012, 48, 3706-3708

91 S. Zhu, C.-H. Su, S. L. Lehoczky, I. Muntele and D. Ila, Diamond Relat Mater, 2003, 12, 1825-1828.

92 R. Guzmán de Villoria, A. J. Hart and B. L. Wardle, ACS Nano, 2011, 5, 4850-4857.

93 S. Aziz, S. A. Rashid, S. Rahmanian, and M. A. Salleh, Polym Compos, 2015, 36, 1941-1950.

94 N. De Greef, L. Zhang, A. Magrez, L. Forró, J.-P. Locquet, I. Verpoest and J. W. Seo, Diamond Relat Mater, 2015, 51, 3948.

95 M. A. Meitl, Y. Zhou, A. Gaur, S. Jeon, M. L. Usley, M. S. Strano and J. A. Rogers, Nano Lett, 2004, 4, 1643-1647.

96 D. P. Long, J. L. Lazorcik and R. Shashidhar, Adv Mater, 2004, 16, 814-819.

97 H.-W. Seo, C.-S. Han, D.-G. Choi, K.-S. Kim, and Y.-H. Lee, Microelectronic Eng, 2005, 81, 83-89.

98 E. Gultepe, D. Nagesha, B. D. F. Casse, S. Selvarasah, A. Busnaina and S. Sridhar, Nanotechnology, 2008, 19, 455309.

99 S. G. Rao, L. Huang, W. Setyawan, and S. Hong, Nature, 2003, 425, 36-37.

100 M. Zhang, P. Boughton, B. Rose, C. S. Lee and A. M. Hong, Int J Biomater, 2013, 396056.

101 C. Ricci, L. Moroni and S. Danti, OA Tissue Engineering, 2013, 1, 4.
102 A. L. Warshaw and C. Fernández-del Castillo, $N$ Engl J Med, 1992, 326, 455-465.

DOI: 10.1039/C6NR09482A

103 E. Deer, J. Gonzalez-Hernandez, J. D. Coursen, J. E. Shea, J. Ngatia, C. L. Scaife, M. A. Firpo and S. J. Mulvihill, Pancreas, 2010, 39, 425-435.

104 A. Bianco, K. Kostarelos and M. Prato, Current Opinion in Chemical Biology, 2005, 9, 674-679.

105 N. W. S. Kam, M. O'Connell, J. A. Wisdom and H. Dai, Proc Nat Ac Sci U.S.A., 2005, 102, 11600-11605.

106 Z. Liu, X. Sun, N. Nakayama-Ratchford and H. Dai, ACS Nano, 2007, 1, 50-56.

107 L. E. Gerweck and K. Seetharaman, Cancer Res, 1996, 56, 1194-1198.

108 I. F. Tannock and D. Rotin, Cancer Res, 1989, 49. 41734384.

109 S. L. Edwards, J. S. Church, J. A. Werkmeister, J. A. M. Ramshaw, Biomaterials, 2009, 30, 1725-1731.

110 A. Abarrategi, M. C. Gutiérrez, C. Moreno-Vicente, M. J. Hortigüela, V. Ramos, J. L. López-Lacomba, M. L. Ferrer, F. del Monte, Biomaterials, 2008, 29, 94-102.

111 S. R. Shin, H. Bae, J. M. Cha, J. Y. Mun, Y.-C. Chen, H. Tekin, H. Shin, S. Farshchin, M. R. Dokmeci, S. Tang, A. Khademhosseini, ACS Nano, 2012, 6, 362-372.

112 E. Hirata, M. Uo, Y. Nodasaka, H. Takita, N. Ushijima, T. Akasaka, F. Watari, A. Yokoyama, J Biomed Mater Res B Appl Biomater, 2010, 93, 544-550.

113 F. M. P. Tonelli, A. K. Santos, K. N. Gomes, E. Lorençon, S. Guatimosim, L. O. Ladeira and R. R. Resende, Int J Nanomed, 2012, 7, 4511-4529.

114 S. R. Shin, S. M. Jung, M. Zalabany, K. Kim, P. Zorlutuna, S. B. Kim, M. Nikkhah, M. Khabiry, M. Azize, J. Kong, K.-T. Wan, T. Palacios, M. R. Dokmeci, H. Bae, X. Tang, A. Khademhosseini, ACS Nano, 2013, 7, 2369-2380. 